\title{
Los testamentos del regente de la Audiencia de Guadalajara don Eusebio Sánchez Pareja (1769-1778)
}

María Pilar Gutiérrez Lorenzo

UNIVERSIDAD DE GUADALAJARA, mapilargutierrez@yahoo.com

\section{INTRODUCCIÓN}

1 hallazgo de tres testamentos de Eusebio Sánchez Pareja,
quien se desempeńó con importantes cargos tanto en la Au-
diencia de la Nueva Galicia como en la Audiencia de México, ejerció primero como oidor en Guadalajara, y después como alcalde del crimen en México, seleccionado por el nuevo secretario de Indias, José de Gálvez, en 1776, para integrar el selecto y reducido grupo de magistrados que introdujeron la función del regente en las audiencias indianas, ocupó este cargo en la Audiencia de Guadalajara desde su implantación en 1776 hasta 1786, momento en que es nombrado regente en México, constituye una fuente hasta ahora no explorada para adentrarse en un personaje clave en el contexto de las Reformas Borbónicas, ya que la creación de esta figura en las audiencias indianas ha sido considerada por los historiadores interesados en el tema una de las reformas más visibles en el camino trazado para la implantación del régimen de intendencias, que para el caso de la Nueva España se reconoce con la promulgación de la Ordenanza de Intendentes en 1786. Cabe señalar que estos tres testamentos abarcan el periodo enmarcado entre los años 1769 y 1778 , corresponden a momentos clave de la vida de Sánchez Pareja como las promociones en su carrera profesional y los consecuentes cambios de destino que conllevan nuevos retos políticos y la máxima 
adhesión al proyecto reformista impulsado por Gálvez; también muestran momentos de incertidumbre como cambiar de lugar de residencia cargando a la familia y encontrar nuevos círculos sociales de acogida. Por otro lado, la temporalidad definida por estos testamentos corresponde a un periodo particularmente intenso para la Nueva Espańa, marcado por un contexto político de cambio que arranca en 1765 con la llegada del visitador José de Gálvez y cierra con la muerte del virrey Bernardo Gálvez en 1786, pocos meses antes del arribo al puerto de Veracruz de la Ordenanza de Intendentes. Pues bien, estos años son precisamente los que corresponden a la intensa actividad profesional desarrollada por Sánchez Pareja en la Nueva España, ya que es en 1764 cuando este burócrata letrado llega a Guadalajara con el nombramiento de oidor debajo del brazo procedente de Cartagena de Indias, donde se había desempeñado durante 8 años como teniente asesor del virrey Solís (1753-1761) y será en 1786, ejerciendo el cargo de regente en la audiencia de México, cuando alcanza la jubilación.

Como se ve en la tabla que se presenta, el primer testamento lo redacta Sánchez Pareja en 1769, siendo oidor de la Nueva Galicia, cargo que venía ocupando desde hacía 5 años. Consta de 17 cláusulas testamentarias y presenta tachaduras en la cláusula 1, 9, 11, 12 y 13, y se localizó en el Archivo de la Audiencia de Guadalajara en el ramo civil. El segundo testamento, fechado en 1773, lo redactó cuatro años después al tener noticia de su promoción a la plaza de alcalde del crimen de la Audiencia de México, momento de gran impacto en su trayectoria profesional y que refleja en el documento al hacer mención de su flamante nombramiento y pronta marcha a la capital, "para donde me hallo próximo a hacer viaje". En este segundo testamento se reducen las mandas y se incluyen las modificaciones realizadas al primer documento, consta de 16 cláusulas y presenta rectificaciones en la parte correspondiente a los testigos. El tercer testamento se realizó cinco años después, en 1778, al momento de ejercer como regente en la Audiencia de Guadalajara, consta de 15 cláusulas y no presenta enmiendas ni tachaduras a la escritura; se podría decir que de los tres testamentos es el que presenta una mayor limpieza en el proceso técnico de ejecución de la escritura. 
Desde el punto de vista documental, el segundo y tercer testamento son protocolos testamentarios localizados en el Archivo de Instrumentos Públicos del Estado de Jalisco, pertenecen al notario Nicolás López Padilla.

La transcripción que se presenta a continuación corresponde al último de los testamentos que redacta Sánchez Pareja, fechado el 11 de marzo de 1778, pues permite interpretar con mayor fiabilidad sus últimas voluntades, así como sus mayores inquietudes ante la idea de la muerte, además de que proyecta una más amplia trayectoria de vida. Hay que señalar que para este estudio introductorio se analizaron los tres documentos con la mira puesta en obtener mayor información sobre las circunstancias bajo las cuales se elaboran los tres testamentos y conocer las peculiaridades que los rodean.

Para empezar, son varias las inquietudes que surgieron a la hora de acometer el análisis de estos testamentos; en primer lugar pudimos constatar que se trata de un personaje no trabajado, pese a ser un actor relevante en la puesta en marcha de las reformas borbónicas en el ámbito de la Nueva España y formar parte del selecto grupo de magistrados peninsulares elegidos personalmente por Gálvez para echar a andar su proyecto desempeñando la función de regente. Tan sólo contamos con dos mínimos esbozos biográficos, el primero es el que realizó en 1948 Juan B. Iguíniz en su obra Los gobernantes de Nueva Galicia, Datos y documentos para sus biografias, en el que el autor hace uso de algunas fuentes para, lejos de presentarnos una biografía detallada de este personaje, ofrecernos notas y documentos de sumo interés, como es su acta de defunción localizada en el Sagrario Metropolitano de México. ${ }^{1}$ Por su parte, Margarita Restrepo Olano, en su trabajo sobre el Virreinato de Nueva Granada en tiempos del virrey Solis (1753-1761), publicado en el 2009, aporta información sacada de su relación de méritos, documento que se encuentra en el Archivo General de Indias de Sevilla en la Sección Audiencia de Santa Fe. ${ }^{2}$ Por otro lado, arañar información

${ }^{1}$ Juan B. Iguíniz, Los gobernantes de Nueva Galicia. Datos y Documentos para sus biografias, 3a ed. (Guadalajara: Secretaría General del Gobierno de Estado de Jalisco, 1981), 127-129.

${ }^{2}$ Una relación de méritos de Eusebio Sánchez Pareja se encuentra en el AGI, Santa 
de estos testamentos y construir su biografía con un perfil más amplio de lo que hasta ahora se conoce nos ha dado resultados sorprendentes, pues, nos pone frente a las estrategias sociales y redes familiares mediante las cuales la carrera de un jurista de origen peninsular se encumbra hasta alcanzar la más alta de las distinciones de las magistraturas novohispanas: la regencia en las Audiencias de la Nueva Galicia y México. Dado que nuestros intereses se centran en el ámbito de la Nueva Galicia, nos ocuparemos mayormente en este primer acercamiento al personaje de su actuación en este ámbito territorial.

Como han demostrado los historiadores interesados en estudiar a los actores que se desempeñaron en las instituciones administrativas de la época moderna al abordar algunos estudios de caso, ${ }^{3}$ Eusebio José Sánchez Pareja contaba con las condiciones familiares para formar parte de la estructura del gobierno de la monarquía hispana en el marco del imperio. Pertenecía -y hace ostentación del ello en un primer testamento-a una familia de gran abolengo que destacaba por méritos y servicios a la Corona, y entre tachones y enmiendas al documentos escrito Sánchez Pareja hacía mención a un antepasado participe de la caballería de Granada en 1563, y reconocía ser descendiente por línea paterna del reino de Murcia -en el levante español-, donde se extravió de la familia un mayorazgo al haber sus parientes dejado estas tierras. Además consideraba demostrable el entronque familiar con los Manuel, linaje de la más alta nobleza castellana que apoyó a la Casa Trastámara en la que fuera la primera Guerra Civil castellana, allá por el siglo xIv, y justificaba "según la dicha tradición" un origen familiar directo del adelantado del reino de Murcia, Juan Sánchez, conde de Carrión. ${ }^{4}$

Fe, 1080, información que salió a la luz en el libro de Margarita Restrepo titulado Nueva Granada en tiempos del virrey Solís, 1753-1761, quien la utiliza para construir el perfil de Sánchez Pareja como segundo asesor y secretario del virrey Solís. Véase Margarita Restrepo Olano, Nueva Granada en tiempos del virrey Solis, 1753-1761 (Bogotá: Universidad del Rosario, 2009), 33-34.

${ }^{3}$ Véase Juan Luis Castellano, Jean Pierre Dedieu y Ma. Victoria López-Cordón, eds., La pluma, la mitra y la espada (Madrid y Barcelona: Universidad de Burdeos, Marcial Pons, 2002).

${ }^{4}$ El condado de Carrión fue una de las ciudades que tradicionalmente había sido 
Con estas credenciales nuestro regente nació Baena, provincia de Córdoba, en 1715, donde su padre, don José Sánchez, había sido administrador de la Real renta de Salinas en aquella villa, su madre, dońa Rosa Francisca de Pareja y de la Torre, era natural de la villa de Doña Mencía. ${ }^{5}$

Esta trayectoria familiar puede que inclinara a un joven Sánchez Pareja a iniciar estudios de filosofía en el Colegio de Santo Domingo de la ciudad de Cádiz, donde cursó tres años, para pasar después al Imperial de San Miguel de la Universidad de Granada, donde realiza estudios de jurisprudencia canónica y obtiene gracia de media beca de propiedad, además de adelantar estudios de bachiller y licenciatura. Según su relación de méritos se graduó en Sagrados cánones en 1738; en 1744 presentó la oposición a la canonjía doctoral de la Universidad de Granada; y en 1741 fue presentado por el rey para una beca canonista del Real Colegio Mayor de Santa Catalina Mártir en esa Universidad. Entre los cargos que ejerció antes de pasar a América se conoce que fue familiar de la Inquisición en su ciudad natal, cargo muy apreciado por cuanto éstos eran auxiliares laicos y gozaban de un gran número de privilegios. ${ }^{6}$ Sin duda, el ejercicio durante cinco

parte del patrimonio de las reinas castellanas y, desde el reinado de Enrique II, había pasado a don Juan Sánchez Manuel junto con el condado del mismo nombre. Miembro de la familia Manuel y primo de la reina Juana, Juan Sánchez formaba parte del grupo de parientes más o menos lejanos de Enrique II que se beneficiaron de las mercedes enriqueñas. A él le correspondió en primer lugar Carrión, pero también se le concedió más adelante el adelantamiento del reino de Murcia. Cfr. Ana Echevarría, Catalina de Lancaster. Reina Regente de Castilla (1372-1418) (Madrid: Nerea, 2002), 74.

${ }^{5}$ Esta villa debe su nombre a la esposa del capitán de Fernando III, D. Alvar Pérez de Castro, Da Mencía López de Haro (1215-1272), dama vizcaína que se convirtió en reina de Portugal tras su boda con el rey Sancho II. Esta villa se independizó en 1653 de Baena, término al que pertenecía.

${ }^{6}$ El familiar-que no hay que confundir con la parentela del inquisidor-, era un auxiliar temporal, no obligado por votos perpetuos. Vestía con tonos severos y lucía venera en el pecho. En esencia era un servidor laico del Santo Oficio listo a cumplir sus deberes al servicio del tribunal como eran la de acompañar a los inquisidores, efectuar detenciones y custodiar a los reos, además de asistir a los autos de fe y ejecutar misiones de apoyo a los tribunales. Se trataba de un cargo muy estimado por las exenciones y beneficios de que gozaban, como la de portar armas para proteger a los inquisidores y la garantía de ser de "sangre limpia". Sobre esta figura jurídica véase: Gonzalo Cerrillo Cruz, "Los familiares de la inquisición española (1478-1700)" (Tesis de doctorado, Universidad Complutense de Madrid, Facultad de Derecho, Departamento de Derecho Constitucional, 01-03-1991). 
años en este empleo al servicio del Santo Oficio le adiestró en el conocimiento de los trámites administrativos y en la puesta en práctica de la legislación para mantener el ámbito jurídico con vista a delimitar las competencias de esta institución frente a otras. Atributos que no pasarían desapercibidos por Gálvez años más tarde, al momento de aterrizar su proyecto reformista en la Nueva Espańa y buscar a los hombres más cualificados para su puesta en marcha.

Con 33 años de edad, en septiembre de 1748, este letrado recibió de la Corona el empleo de Auditor de Gente de la Plaza de Cartagena, con honores de oidor de la Audiencia de Santo Domingo. Un año después, en septiembre de 1749 , lo encontramos en Cádiz presto a atravesar por primera vez el Atlántico y tomar posesión del que fuera su primer destino en el continente americano. El joven Sánchez Pareja viajaba sólo de familia, pues, en ese momento estaba soltero "sin sujeción a estado de matrimonio, ni otro que le impida la libertad de su persona". ${ }^{7}$ Tenía licencia para pasar a Indias acompañado de dos criados, don Salvador Sánchez García, de 19 años de edad y natural de Cádiz, y don Domingo Ignacio Marbella y Caballero, de 23 años y natural de Baena, quienes al igual que Sánchez Pareja presentaron sus respectivas informaciones para justificar que eran "cristianos viejos, solteros y no de los prohibidos a pasar a los [Reynos] de Yndias". Sánchez Pareja también obtuvo licencia para embarcar "dos baúles para ropa de su uso y libros". ${ }^{8}$ Es posible que el futuro regente, entre otros libros, llevara aquellas obras jurídicas necesarias para la aplicación del derecho indiano. Aunque hasta el momento no se ha localizado en los repositorios documentales la biblioteca de este magistrado indiano, algo que sí ha sucedido con otros actores regionales de las reformas borbónicas, como es el caso de Eusebio Bentura Beleña, magistrado con quien coincidiría nuestro personaje en la Audiencia de Guadalajara al momento de la expulsión de los jesuitas, ${ }^{9}$ es innegable pensar que a lo

${ }^{7}$ Archivo General de Indias (AGI), Contratación 54, N1, R.36. 1749.

${ }^{8}$ Ibidem.

${ }^{9}$ Manifiesto de Eusebio Bentura Beleña, edición, introducción y notas, Ignacio Almada Bay et al. (Zamora: El Colegio de Michoacán, Universidad de Guadalajara, El Colegio de Sonora, 2006); y María Pilar Gutiérrez Lorenzo, "La Biblioteca del Oidor Eusebio 
largo de su trayectoria profesional conformara una biblioteca jurídica de cierta envergadura para auxiliarse en su desempeńo como jurista y tener a la mano todas las disposiciones normativas vigentes en las Indias. Pistas acerca de cómo fue adquiriendo su biblioteca las encontramos en su testamento donde manifiesta cómo a través de sus apoderados en la corte conseguía los libros publicados en cada momento en Madrid y Europa (cláusula 7), también vemos su nombre en la lista de suscriptores de la Recopilación sumaria de Bentura Beleña, obra impresa en dos gruesos volúmenes en México por don Felipe de Zúñiga y Ontiveros y que, como señala Diego-Fernández Sotelo, "supuestamente venía a cubrir el espacio que iba de 1677, año de la publicación de los autos acordados de la Audiencia de México por parte del oidor Francisco de Montemayor, al de 1787 , cuando Beleña daba luz a su propia Recopilación sumaria". ${ }^{10}$

Con la llegada a Cartagena de Indias de Eusebio Sánchez Pareja, en 1749 , se inicia la trayectoria americana de este peninsular, quien se desempeñó durante siete años como auditor de gente de guerra en esta plaza, uno de los puntos neurálgicos de la política comercial indiana. A este puerto llegaban los galeones procedentes de España, y de ahí salían cargados de mercancías hacia Portobelo, a celebrar la feria comercial, y luego a la Habana; además el puerto era el ingreso para llegar a las ricas minas de oro y plata del interior de la gobernación. Por todo lo anterior, Cartagena de Indias se manifestaba como una de las llaves de las Indias, y objetivo en sí misma para las potencias enemigas de la monarquía hispana. ${ }^{11}$ Aunque no tenemos infor-

Bentura Beleña 1737-1794. Carácter ideológico e inquietud cultural”, en La biblioteca del oidor Eusebio Bentura Beleña, María Mantilla Trolle y Luz María Pérez Castellanos, 51-74 (Guadalajara: Universidad de Guadalajara, PROMEP, 2012).

${ }^{10}$ Rafael Diego-Fernández Sotelo, El proyecto de José de Gálvez de 1774 en la Ordenanza de Intendentes de Río de la Plata y Nueva España (Zamora: El Colegio de Michoacán, 2017), 139.

${ }^{11}$ Sobre las condiciones locales del virreinato de la Nueva Granada durante la primera mitad del siglo xvin en el contexto de la política de la monarquía española, véase Francisco A. Eissa-Barroso, "La Nueva Granada en el sistema de Utrecht: Condiciones locales, contexto internacional, y reforma institucional" en Resonancias Imperiales. América y el Tratado de Utrecht de 1713, coord. Iván Escamilla González, Matilde Souto Mantecón y Guadalupe Pinzón Ríos, 47-78 (México: Instituto de Investigaciones Dr. José María Luis Mora, Universidad Nacional Autónoma de México, 2015). 
mación sobre las acciones realizadas por el joven Sánchez Pareja en el ejercicio de este oficio, es de suponer que fue acusado y estratégico en una ciudad que aún vivía con el recuerdo del ataque protagonizado en 1741 por el almirante Vernon.

Por la información testamentaria (cláusula 9) se concluye que Sánchez Pareja consiguió insertarse sin mayor problema en la sociedad cartagenera y tuvo tratos comerciales con don Francisco Álvarez de Castro, un importante vecino encumbrado con el título de marqués de Bellestar, perteneciente a uno de los clanes familiares locales con redes y alianzas que alcanzaban los asientos audienciales y el Tribunal de Cuentas de Santa Fe. ${ }^{12}$ Esta relación comercial se basó en una estrecha confianza entre ambos individuos, amistad que permitió a Sánchez Pareja acceder a un préstamo de 8,000 pesos con el que costear un viaje de regreso a Espańa, entre 1753 y 1755, posiblemente en busca de un mejor empleo.

Cabe suponer que como resultado de las gestiones realizadas en la corte de Madrid y por los logros obtenidos en las comisiones que años antes le había encomendado el virrey Pizarro (1749-1753) para organizar los resguardos en la provincia de Cartagena y así poner fin al complejo problema de las tierras en los pueblos de indios, ${ }^{13}$ Sánchez Pareja regresó con el nombramiento de asesor segundo del virrey José Solís (1753-1761), en calidad de secretario, quien le confirió, en 1757, la comisión de indultos y composiciones de tierras en la provincia de Cartagena, actividad que desarrolló durante siete años, hasta su nombramiento como oidor de la Audiencia de Guadalajara en $1764 .^{14}$

A la lista de méritos alcanzados por Sánchez Pareja durante los trece años que permaneció en la ciudad de Cartagena poniendo en marcha la reforma administrativa de la Nueva Granada, ${ }^{15}$ se suma

${ }^{12}$ Mark A. Burkholder y D. S. Chandler, De la impotencia a la autoridad. La Corona española y las Audiencias en América 1687-1808 (México: Fondo de Cultura Económica, 1984), 71, n. 91, 258, 344.

${ }^{13}$ María Dolores González Luna, "Los resguardos de Santa Marta y Cartagena en la segunda mitad del siglo xviII", Boletín Americanista (31) (1981): 66.

${ }^{14}$ Buen Retiro, 18-junio-1764. Título de oidor de la Audiencia de Guadalajara a don Eusebio Sánchez Pareja.

${ }^{15}$ Cabe señalar que fueron 13 años la permanencia de Sánchez Pareja en Cartagena 
su estrategia de inserción social y vinculación con la elite local al contraer matrimonio con dońa María Luisa de Narváez, hija de los condes de Santa Cruz de la Torre, una de las familias más notables de la ciudad, cuyos miembros acaparaban los más altos cargos de la administración civil y eclesiástica, así como del ejército. Tal y como se desprende de la información proporcionada por los testamentos, su suegro era Juan Salvador Narváez y Berrio, un peninsular que inició carrera en 1721 como cadete en el batallón fijo de Cartagena de Indias, y había ocupado importantes cargos en el cabildo de la ciudad llegando a ser gobernador de Girón. Su suegra, la condesa de Santa Cruz de la Torre, pertenecía a una de las familias criollas más notables de Cartagena, cuya fortuna sirvió para financiar militarmente esta plaza. ${ }^{16}$ Cabe mencionar también a D. Antonio de Narváez, uno de sus cuñados, destacado militar que llegó a ser mariscal de campo y gobernador de Santa Marta, Cartagena y Panamá; así como a Bartolomé de Narváez y Berrio, tío de su esposa, uno de los dos únicos criollos que alcanzó la silla episcopal de Cartagena.

No cabe duda que todo este capital relacional redundaría en beneficio de este burócrata al servicio de la monarquía hispana y en su desempeño como teniente asesor próximo a las decisiones del virrey. Pese a que no disponemos de estudios puntuales de su gestión durante estos ańos, a tenor de los muchos años que permaneció en Cartagena, y a la promoción que significó su nuevo destino, cabe pensar en un desempeño notable puesto que en 1764 fue llamado a ocupar una de las magistraturas en la Audiencia de Guadalajara.

De Cartagena partió Sánchez Pareja rumbo a la Nueva Galicia en compañía de su mujer y un hijo adoptivo de pocos meses, José Sánchez Pareja, quien en Guadalajara seguiría la carrera sacerdotal, del que no se supo quiénes eran sus padres, y sólo se tenían indicios de "que fueron personas de distinción y de calidad de Cartagena" (cláusula 6), lo cual pone de manifiesto las solidaridades desplegadas entre los miembros de la elite local para proteger a los hijos habidos

de Indias ya que aunque llegó en 1749 y salió con destino a Guadalajara en 1764, viajó a Espańa donde estuvo dos años.

${ }^{16}$ Cfr. Margarita Restrepo Olano, Nueva Granada en tiempos del virrey Solis, 17531761 (Bogotá: Universidad del Rosario, 2009), 191. 
fuera del matrimonio, así como el vertiginoso encumbramiento social que se lograba gracias a la alianza entre miembros de la administración y descendientes de acaudaladas e influyentes familias criollas para, como en este caso, adquirir la encomienda de educar a este menor.

Aunque falta por identificar para la Audiencia de la Nueva Galicia algunas de las transformaciones tempranas del reformismo borbónico que, según las aportaciones historiográficas más recientes, vendrían a echar por tierra la tesis de Burkholder y D.S. Chandler de un siglo xviII dividido entre una "era de la impotencia" y una "era de la autoridad", donde sólo a partir de 1750 la Corona empezó a implementar medidas reformistas en las audiencias americanas, ${ }^{17}$ el arribo a Guadalajara en 1764 de Sánchez Pareja representaba un modelo de ministro curtido con base en años de servicio y amplia experiencia de gobierno. Por otro lado, tal y como lo reflejan los expedientes conservados en el Archivo de la Audiencia, este tribunal había tenido que afrontar ciertos problemas en relación con la dotación de sus plazas puesto que durante varias décadas había sido una práctica la compra de cargos supernumerarios y la "radicalización" de sus miembros, ya que la mayoría de sus ministros tenía más de cinco años en el cargo por falta de promoción dada la escasez de vacantes en la Audiencia de México. ${ }^{18}$ Además se daba el caso de que algunos de los compradores de los cargos eran nacidos en la Nueva Galicia, como Francisco López Portillo y José Manuel de la Garza Falcón; por su parte, Francisco Gómez Algarín estaba casado con una lugareña, lo cual suponía un menoscabo más para el buen funcionamiento del tribunal. ${ }^{19}$

Así las cosas, la entrada de Sánchez Pareja en la Audiencia de Guadalajara formaba parte del plan ministerial, con Julián Arriaga al frente de la Secretaría de Marina e Indias, para atajar el problema

${ }^{17}$ Cfr. Francisco A. Eissa-Barroso, "'The Honor of the Spanish Nation': Military Officers, Mediterranean Campaigns and American Government under Felipe V", en Early Bourbon Spanish America. Politics and Society in a Forgotten Era (1700-1759), coord. Francisco A. Eissa-Barroso y Ainara Vázquez Varela, 39-60 (Leiden y Boston: Brill, 2013).

${ }^{18}$ Mark A. Burkholder y D. S. Chandler, De la impotencia, 89, 91, 176.

${ }^{19}$ Ibidem, 130. 
de las Audiencias Indianas, por lo que su inserción dio pie a crear un clima hostil en la Audiencia por significar el reemplazo de los antiguos ministros criollos para dar cabida al ideario ilustrado de la reforma. La permanencia de Sánchez Pareja en la Audiencia de Guadalajara, hasta su promoción a la de México, fue de nueve años, de 1764 a 1773. Durante este tiempo nacieron sus tres hijos, y los tres fueron bautizados en la catedral por mano del obispo en turno. Cabe señalar su destacada actuación en esta primera etapa en la Audiencia novogalaica como oidor al frente del juzgado de bienes de difuntos, gestión que recibió la aprobación del monarca que celebró su estructurada organización; ${ }^{20}$ también tuvo Sánchez Pareja particular interés en el progreso de la ciudad, como comisionado de la Audiencia, en las obras de composición y reparo de las calles, ${ }^{21} \mathrm{y}$ entre las iniciativas promovidas para dar cauce al estancamiento de los procesos judiciales por la falta de espacio en el tribunal, estuvo la solicitud de su traslado al Colegio de los Jesuitas tras su expulsión. ${ }^{22}$

Por otra parte, su incondicional lealtad al proyecto de reforma quedó de manifiesto en el enfrentamiento que junto con el fiscal de la Audiencia, don Domingo de Arangoiti, mantuvo en 1769 en contra del obispo de Guadalajara, don Diego Rodríguez de Rivas, un criollo nacido en Ecuador, quien en varias cartas pastorales se había declarado contrario a la política de Gálvez y expulsión de los jesuitas. El ataque de los magistrados se sostenía en la denuncia por faltar a su ministerio, ya que alegaban hacía dejación de sus funciones y no cumplía con la obligatoriedad de las visitas pastorales de su jurisdicción. La acusación fue considerada infundada por el monarca, lo cual supuso un varapalo para los nuevos magistrados de la Audiencia, quienes se sintieron agraviados por lo que consideraban era un freno a la política regalista de los borbones y tener que acudir al palacio episcopal a presentar sus disculpas. ${ }^{23}$

${ }^{20}$ Archivo de la Real Audiencia de Guadalajara (ARAG), Bienes de Difuntos, caja 102, exp. 3, 1771.

${ }^{21}$ ARAG, Ramo Civil, caja 91, exp. 8, 1768.

${ }^{22}$ ARAG, Ramo Civil, caja 67, exp. 10, 1767.

${ }^{23}$ ARAG, Ramo Civil, caja 339, exp. 9, 1768. 
En 1773, Sánchez Pareja es nombrado alcalde del crimen de la Audiencia de México y se traslada a la capital con su mujer e hijos. Esta primera etapa de estancia en Guadalajara le proporcionó la experiencia de trabajar en un tribunal y establecer relaciones personales con otros actores protagónicos de esta etapa de reformas, como lo fue Eusebio Bentura Beleńa, a quien Gálvez nombró subdelegado visitador de las cajas y ramos de la Real Hacienda de Guadalajara (1787) y le comisionó para supervisar y dar cumplimiento en esta ciudad a la expulsión de los jesuitas (1768).

En 1776, con el nombramiento de regente debajo del brazo, el regreso a Guadalajara, después de tres años de ausencia en México, se vislumbra con otros ojos. Ahora el flamante magistrado ocupaba un cargo de nueva creación y eran otros los honores que le correspondían, también los retos mucho más vastos. Durante los diez años que Sánchez Pareja asumió la regencia de Guadalajara tuvo particular interés en el progreso material de la Nueva Galicia, consiguiendo numerosas realizaciones para sus habitantes: mitigar el hambre frente a la crisis agrícola de 1785-1786 y proponer medidas para frenar las epidemias desatadas; impulsar la propuesta de edificación de un hospital a instancias del obispo fray Antonio Alcalde; promover el fortalecimiento de la Audiencia solicitando la creación del empleo de secretario de cámara y presidencia, "a imitación de los que se hallan establecidos en los virreinatos de México, Lima y Santa Fe", para hacer más expedita la administración de justicia; ${ }^{24}$ además de levantar, gracias a su particular celo, el mapa de los curatos de la Nueva Galicia una obra de gran envergadura que supuso aprovechar gran número de datos estadísticos; ${ }^{25}$ así como la ampliación del servicio de correos estableciendo nuevas estafetas. ${ }^{26}$

Sánchez Pareja también se empeñó en otorgar preeminencia a su nuevo cargo, por lo que reivindicó el nombramiento de capitán

${ }^{24}$ ARAG, Civil, caja 345, exp. 1, 1777,

${ }^{25}$ Christian Duverger, "Le plano de Senticpac e Yscuintla (Nouvelle-Galice): une carte indigène mexicaine du XVIIIe siècle”, Mélanges de la Casa de Velázquez (25) (1989): 303-326.

${ }^{26}$ Juan B. Iguíniz, Los gobernantes, 128. 
general que hasta ese momento se había usado con cierta despreocupación, lo cual consiguió, señala María del Carmen Velázquez, “como premio a su terquedad". Así, en 1784, logró añadir al título de regente y presidente de Audiencia de la Nueva Galicia, el de "Comandante General de las Armas del Gobierno de Guadalajara". ${ }^{27}$

No resulta ajeno pensar que Sánchez Pareja durante su regencia prestara particular empeño en perfilar las facultades de su nuevo cargo y dar brillo al tribunal tapatío, para así mostrar una institución de nueva planta transformada bajo los parámetros de la reforma audiencial y de ahí el tesón puesto en guardar el protocolo y la denuncia ante el rey del desplante que sintió al momento de su entrada pública en Guadalajara, pues, encontró a fray Antonio Alcalde "de redondo y no con capa magna". La queja fue zanjada por el fiscal del Consejo de Indias, ordenando la aplicación de las Leyes de Indias para que en el futuro el obispo de Guadalajara se abstuviera de semejantes desaires, obligándole a llevar la capa sobre los hombros en sus visitas a Palacio "para su arrastre" ante el nuevo magistrado. ${ }^{28}$

En 1786, por Real Cédula de 18 de marzo, Sánchez Pareja fue nuevamente promovido, con el nombramiento de regente, a la $\mathrm{Au}$ diencia de México; en ese momento contaba con 71 años y había llegado a la cumbre de su carrera dentro de la administración de la monarquía hispana, y a una de las arterias por donde corría el plan de reforma de Gálvez: la capital del virreinato novohispano. Ese mismo año, el 30 de noviembre de 1786, el impulso de esta reforma dejó de latir con el desenlace de la enfermedad y muerte del virrey Bernardo de Gálvez, sobrino del Ministro de Indias. Por su condición de regente de la Audiencia de México, esta circunstancia ponía al ahora experimentado y maduro Sánchez Pareja al frente del virrei-

${ }^{27}$ María del Carmen Velázquez, "La jurisdicción militar en la Nueva Galicia”, Historia Mexicana $\mathrm{Ix}(1)$ (julio-septiembre 1959): 15-34.

${ }^{28}$ AGI, Guadalajara, leg. 343, La capa magna o también llamada falda en el siglo XviII, era una capa con una larga cola -de unos cinco metros-, que si bien se podía llevar enrollada sobre el brazo, era común lucirla extendida con ayuda de un caudatorio, fabricada en lana morada para los obispos y en seda púrpura para los cardenales. 
nato novohispano ya que el 8 de noviembre, al límite de sus fuerzas, el virrey había depositado el gobierno en la Audiencia. Para entonces, la reforma administrativa de las intendencias ya estaba en marcha y se habían nombrado los primeros intendentes, de los cuales el de Puebla y Guanajuato, Manuel de Flon y Antonio Riaño, eran cuñados del difunto virrey. Meses después, Carlos III firmaba la Real Ordenanza de Intendentes de la Nueva Espańa y en el virreinato se producía un cambio de rumbo con la renuncia de algunos miembros del clan de los Gálvez. El 28 de abril de 1787, el arzobispo de México, Alonso Núnez de Haro y Peralta, tomaba las riendas del virreinato por un periodo de cuatro meses, desplazando así a la audiencia gobernadora del ejercicio de sus funciones.

No son pocos los autores que en esta sucesión de acontecimientos políticos muestran a un regente viejo y enfermo deseoso de alcanzar la jubilación ${ }^{29}$ y es posible que así fuera, sin embargo, la muerte del ministro de Indias el 17 de junio de ese ańo (1787), y la rapidez con la que se le concede a Sánchez Pareja su solicitud de jubilación, ${ }^{30}$ nos llevan a pensar en una pérdida de influencia tras la desaparición del clan Gálvez, y en la entrada a una nueva etapa del proyecto reformista en la que el experimentado burócrata, conocedor del sistema político institucional y de los resortes del cambio diseñado por Gálvez, ya no tiene cabida. El 26 de octubre de 1799, moría en la ciudad de México el que fuera regente en la Audiencia de Guadalajara y, tal como dispuso en su testamento, su cadáver fue depositado en la iglesia del convento de San Francisco de aquella ciudad. ${ }^{31}$

${ }^{29}$ Cfr. Adolfo Rubio Gil, "Alonso Núñez de Haro" en Los virreyes de Nueva España en reinado de Carlos III, vol. 2, ed. José Antonio Calderón Quijano, 363 (Sevilla: Escuela de Estudios Hispano Americanos, 1968).

${ }^{30}$ San Ildefonso, 28-septiembre-1787. S. M. concede a don Eusebio Sánchez Pareja, regente de la Real Audiencia de México, jubilación de esta plaza.

${ }^{31}$ Juan B. Iguíniz, Los gobernantes, 129. 


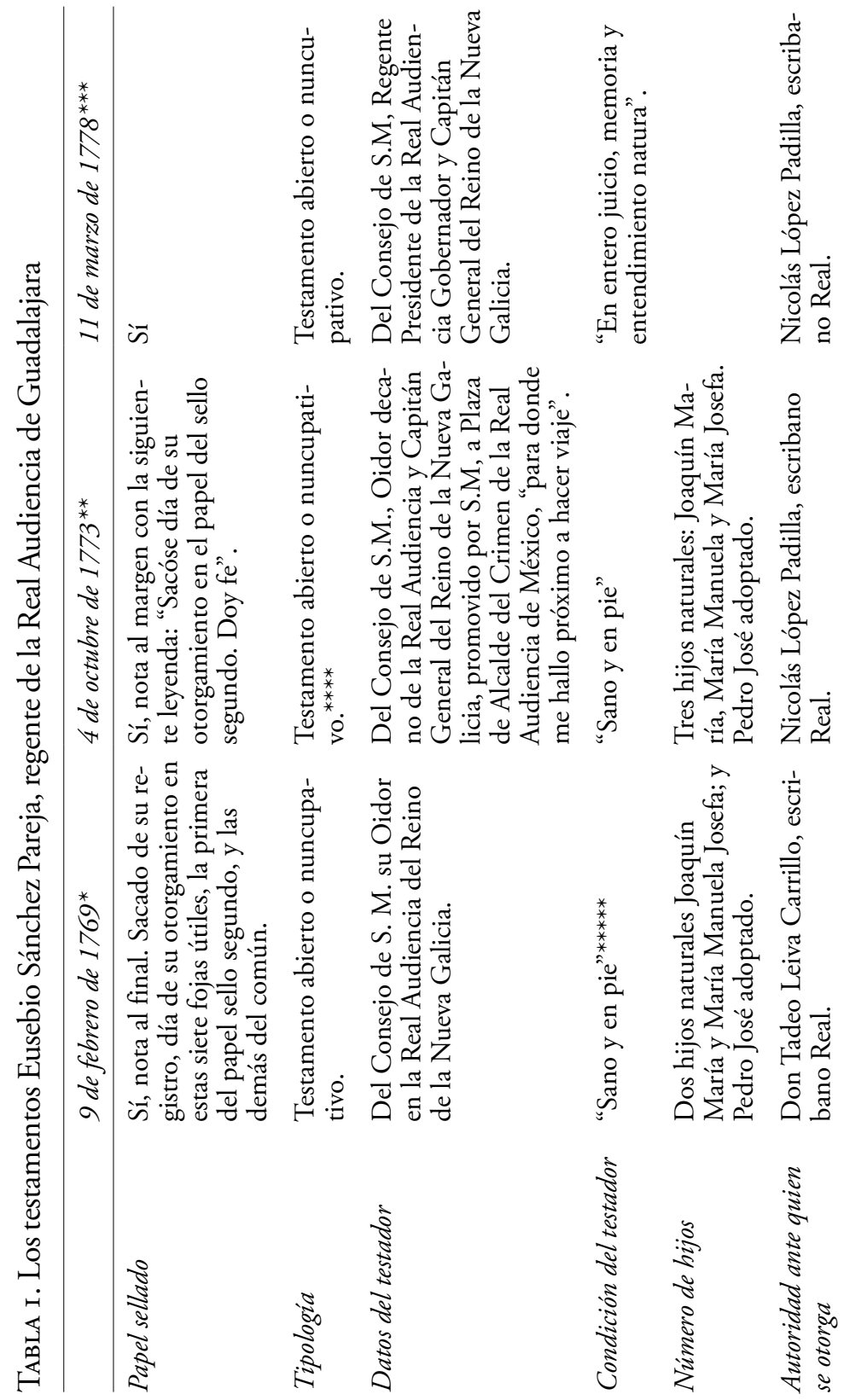




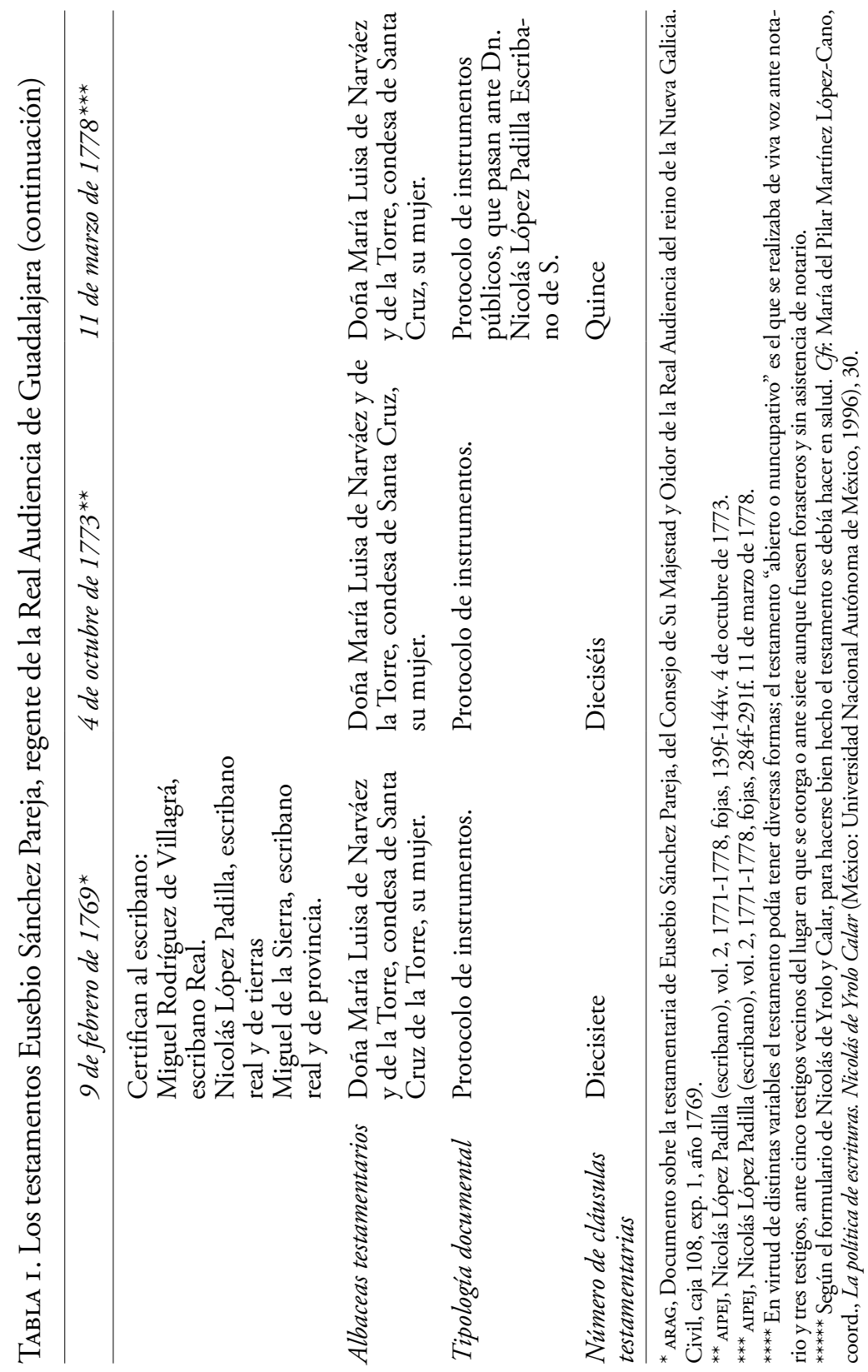




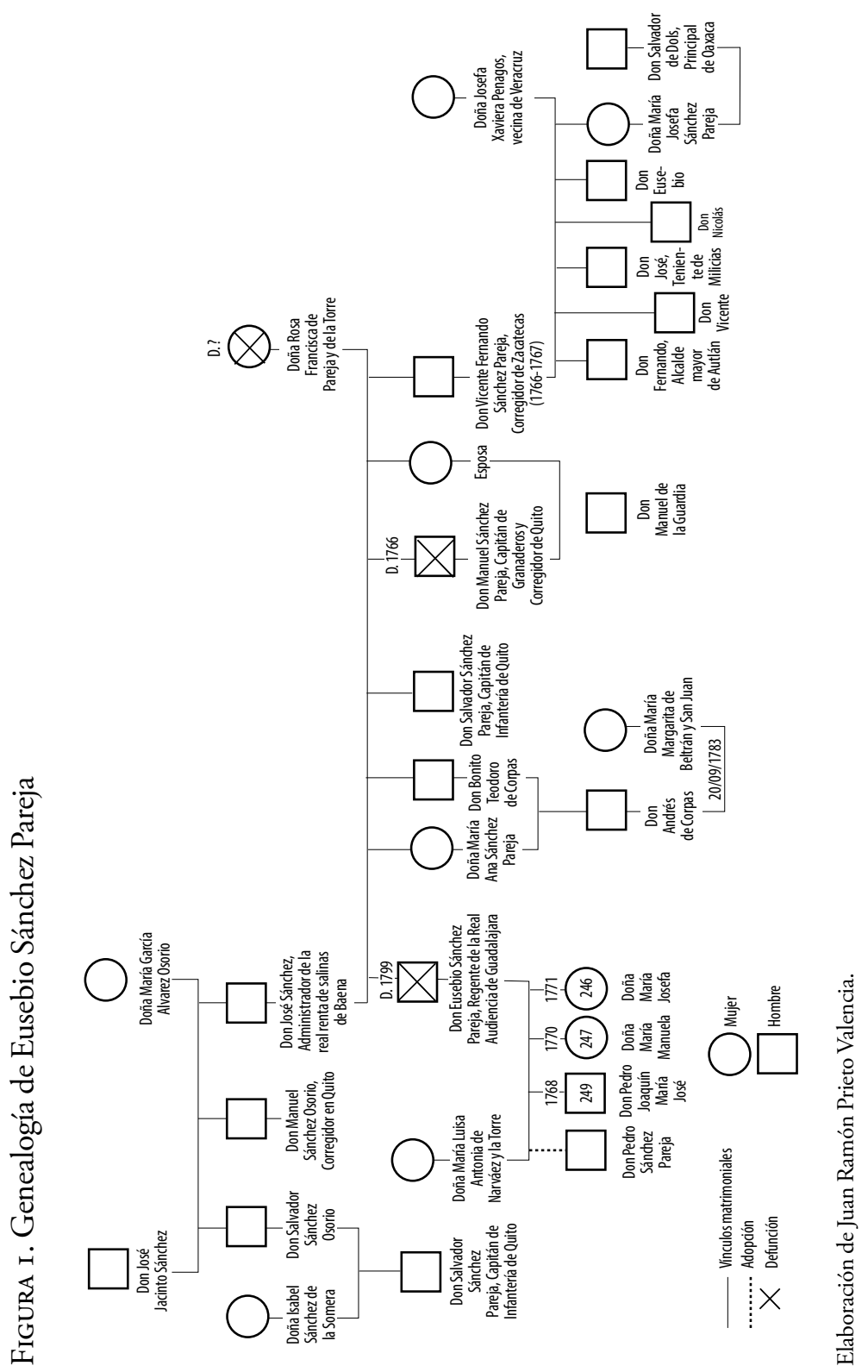




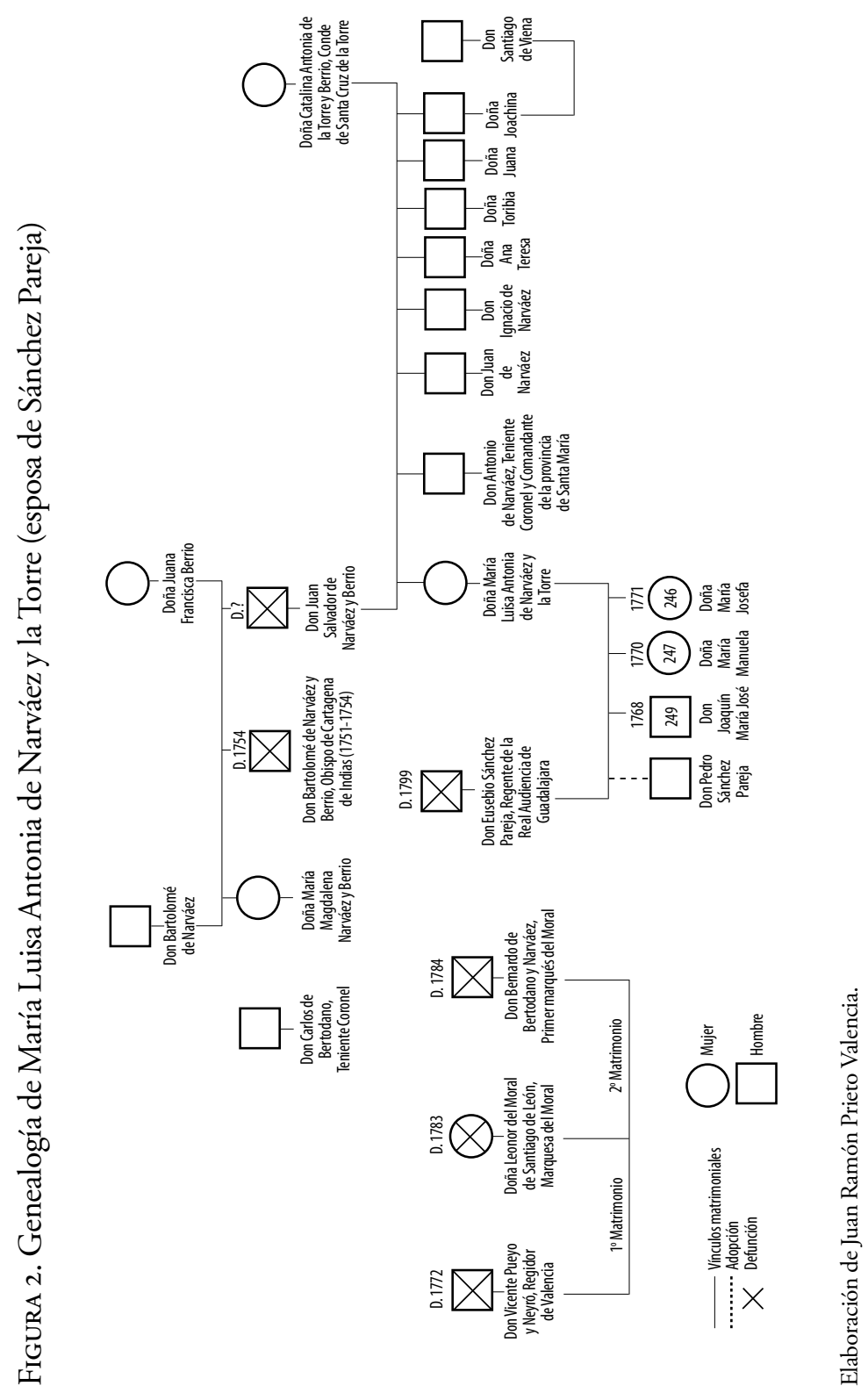




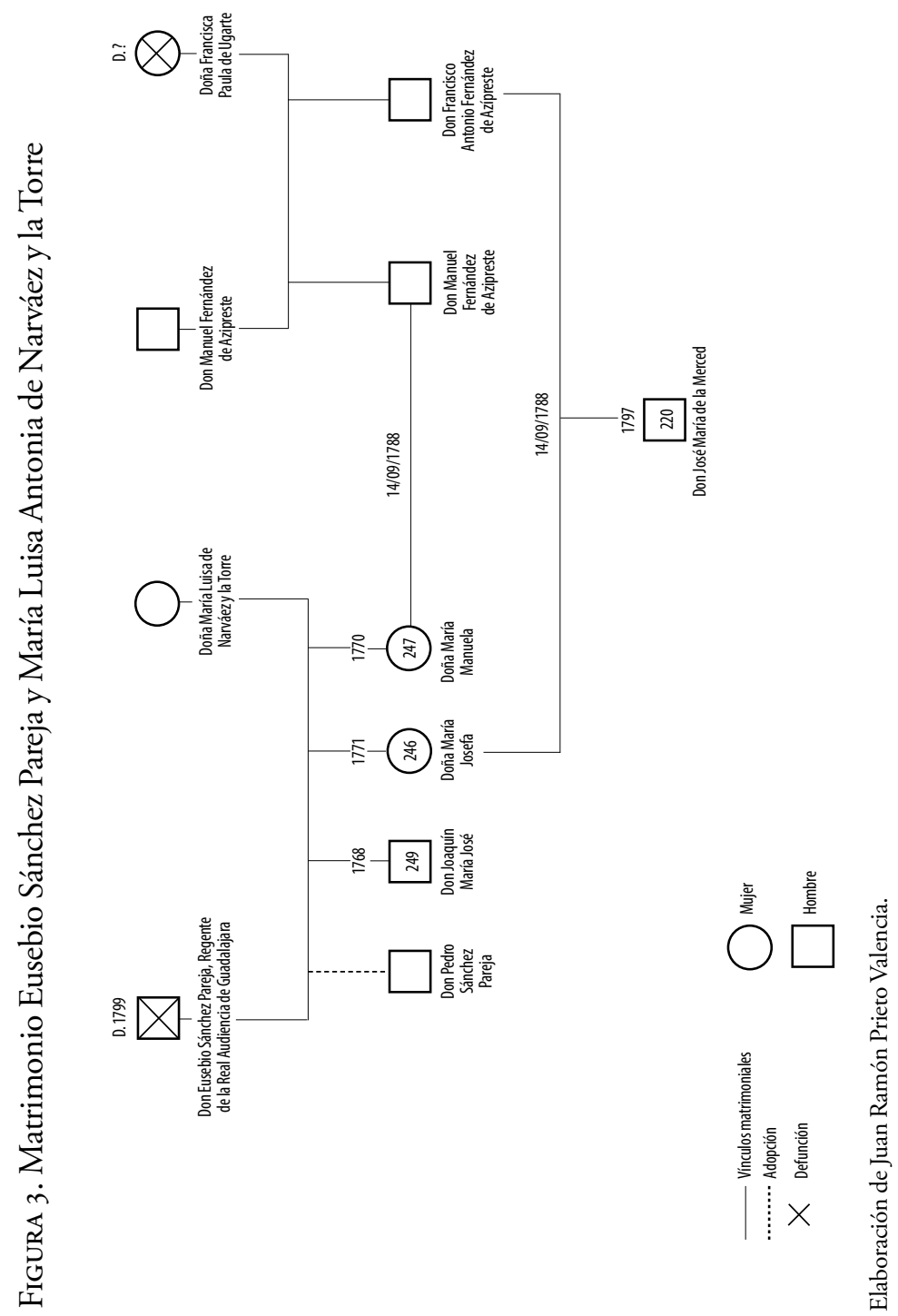




\section{Fuentes}

Instrucción de lo que deben observar los Regentes de la Audiencias de América: Sus Funciones, Regalías, cómo se han de haber con los Virreyes, y Presidentes, y estos con aquellos. Aranjuez, 20 de junio de 1776.

(AIPEj) Archivo de Instrumentos Públicos del Estado de Jalisco (AGI) Archivo General de Indias

(ARAG) Archivo de la Real Audiencia de Guadalajara. Ramo Civil; Ramo Bienes de Difuntos

Bibliografía

Álamo Martell, Ma. Dolores. "Los regentes y la presidencia de la Real Audiencia de Canarias en el siglo XVIII". En XX Coloquio de Historia Canario-Americana. Las Palmas de Gran Canaria: Cabildo Insular de Gran Canaria, 2012.

Burkholder, Mark A. y D. S. Chandler. De la impotencia a la autoridad. La Corona española y las Audiencias en América 16871808. México: Fondo de Cultura Económica, 1984.

Carbajal López, David. "Los años del hambre en Bolaños (17851786). Conflictos mineros, escasez de maíz y sobremortalidad. Relaciones Estudios de Historia y Sociedad $\operatorname{xxxI}(121)$ (invierno 2010): 57-81.

Castellano Juan Luis, Jean Pierre Dedieu y Ma. Victoria LópezCordón, eds. La pluma, la mitra y la espada. Madrid y Barcelona: Universidad de Burdeos, Marcial Pons, 2002.

Castro GutiÉrRez, Felipe. Informe sobre las rebeliones populares de 1767 y otros documentos inéditos. México: Universidad Nacional Autónoma de México, 1990.

Cerrillo Cruz, Gonzalo. "Los familiares de la inquisición española (1478-1700)". Tesis de Doctorado, Universidad Complutense de Madrid, Facultad de Derecho, Departamento de Derecho Constitucional, 01-03-1991.

Diego-Fernández Sotelo, Rafael. El proyecto de José de Gálvez de 
1774 en la Ordenanza de Intendentes de Río de la Plata y Nueva España. Zamora: El Colegio de Michoacán, 2017.

Duverger, Christian. "Le plano de Senticpac e Yscuintla (Nouvelle-Galice): une carte indigène mexicaine du XVIIIe siècle”. Mélanges de la Casa de Velázquez (25) (1989): 303-326.

Eissa-Barroso, Francisco A. "La Nueva Granada en el sistema de Utrecht: Condiciones locales, contexto internacional, y reforma institucional". En Resonancias Imperiales. América y el Tratado de Utrecht de 1713, coord. Iván Escamilla González, Matilde Souto Mantecón y Guadalupe Pinzón Ríos, 47-78. México: Instituto de Investigaciones Dr. José María Luis Mora, Universidad Nacional Autónoma de México, 2015.

“'The Honor of the Spanish Nation': Military Officers, Mediterranean Campaigns and American Government under Felipe V". En Early Bourbon Spanish America. Politics and Society in a Forgotten Era (1700-1759), coord. Francisco A. EissaBarroso y Ainara Vázquez Varela, 39-60. Leiden y Boston: Brill, 2013.

FloreK, Karol. "Cultures of Rebelliousness and Repression in a Mining City: Guanajuato, 1766-1767”. Tesis, BA (Hons) History, University of Sydney, 2008.

Gálvez Ruiz, María Ángeles. "Un proyecto de nuevo gobierno para las provincias occidentales del Pacífico novohispano". Secuencia (93) (septiembre-diciembre de 2015): 7-15.

Gayol, Víctor. Laberintos de justicia. Procuradores, escribanos y oficiales de la Real Audiencia de México (1750-1812). 2 vols. Zamora: El Colegio de Michoacán, 2007.

Gutiérrez Lorenzo, María Pilar. "La Biblioteca del Oidor Eusebio Bentura Beleña 1737-1794. Carácter ideológico e inquietud cultural". En La biblioteca del oidor Eusebio Bentura Beleña. María Mantilla Trolle y Luz María Pérez Castellanos. Guadalajara: Universidad de Guadalajara, PROMEP, 2012.

Iguínız, Juan B. Los gobernantes de Nueva Galicia. Datos y Documentos para sus biografias, 3a ed. Guadalajara: Secretaría General del Gobierno de Estado de Jalisco, 1981.

Manifiesto de Eusebio Bentura Beleña, edición, introducción y notas, 
Ignacio Almada Bay et al. Zamora: El Colegio de Michoacán, Universidad de Guadalajara, El Colegio de Sonora, 2006.

Martínez Garnica, Armando y Daniel Gutiérrez Ardilla, editores académicos, Quién es quién en 1810. Guía de forasteros del Virreinato de Santa Fe. Colección Memoria viva del Bicentenario. Bogotá: Editorial Universidad del Rosario, 2010, 23.

Martínez López-Cano, María del Pilar, coord. La política de escrituras. Nicolás de Yrolo Calar. México: Universidad Nacional Autónoma de México, 1996.

. "El costo de una pronta salvación en Nueva España, siglos XVI-XVII". Revista de Historia y Ciencias Sociales Palimpsesto 1(2) (2004): s/p.

Oliver SÁnchez, Lilia V. "La importancia de los registros hospitalarios para el análisis de la epidemia y escasez de alimentos en Guadalajara, 1785-1786". Letras Históricas (3) (otoño-invierno 2010): 47-67.

Ortiz, Sergio Elías, comp. Escritos económicos. Antonio de Narváez, Ignacio Pombo. Bogotá: Archivo de la Economía Nacional, Colección Bicentenario, Banco de la República, 2010, 13.

Paniagua Pérez, Jesús. "Un intento de reactivación en el Quito del siglo XVIII. La fábrica de Loza fina”. Estudios de Historia Socialy Económica de América Latina, (12) (1995): 93-116.

Pietschmann, Horst. "Un testimonio del impacto del reformismo borbónico en Nueva Espańa: la representación del intendente de Puebla de los Ángeles de 27 de junio de 1792". Jahrbuch für Geschichte Lateinamerikas (31) (1994): 1-38.

Porras Muñoz, Guillermo. "Hace doscientos años: 'México llorosa", Estudios de Historia Novohispana 10(010) (1991).

Real Ordenanza para el establecimiento é instrucción de intendentes de exército y provincia en el reino de la Nueva Galicia. Edición anotada de la Audiencia de la Nueva Galicia, eds. Marina Mantilla Trolle, Rafael Diego-Fernández y Agustín Moreno Torres. México: Universidad de Guadalajara, El Colegio de Michoacán, El Colegio de Sonora, 2009.

Restrepo Olano, Margarita. Nueva Granada en tiempos del Virrey Solis, 1753-1761. Bogotá: Editorial Universidad del Rosario, 2009. 
Rodríguez García, Vicente. El fiscal de Real Hacienda en Nueva España: D. Ramón de Posada y Soto, 1781. Oviedo: Secretariado de Publicaciones de la Universidad de Oviedo, 1985.

Rubio GiL, Adolfo. "Alonso Núñez de Haro". en Los virreyes de Nueva España en reinado de Carlos Carlos III, ed. José Antonio Calderón Quijano. Sevilla: Escuela de Estudios Hispano- Americanos, 1968.

Sanciñena Asurmendi, Teresa. La Audiencia en México en el reinado de Carlos III. México: Universidad Nacional Autónoma de México, 1999.

Sheridan, Thomás E. Empire of Sand. The Seri Indians and the Struggle for Spanish Sonora, 1645-1803. Tucson: The University of Arizona Press, 1999.

Soberanes, José Luis. "El estatuto del regente de la Audiencia de México (1776-1821)". Anuario de Estudios Americanos (32) (1975): 415-446.

TAU, Víctor. El taller del jurista. Sobre la colección Documental de Benito de la Mata Linares, Oidor, Regente y Consejero de Indias. Cátedras de Excelencia. Madrid: Universidad Carlos III, Santander, 2011.

Tuelis, José y José Luis Duro Torrijos. "Los cinco testamentos de Francisco Xavier Balmis". Gaceta Médica de México 148(4) (2012): 411-418.

VelázQuez, María del Carmen. "La jurisdicción militar en la Nueva Galicia”. Historia Mexicana IX(1) (julio-septiembre 1959). 


\title{
Documento $^{32}$
}

Archivo Instrumentos Públicos del Estado de Jalisco (AIPEJ) Nicolás López Padilla (escribano), Vol. 2, 1771-1778, fojas, 284f-291f. 11 de marzo de 1778.

[f. 284] Protocolo de instrumentos públicos, que pasan ante $\mathrm{D}^{\mathrm{n}}$. Nicolás López Padilla E de S.M., y comienza en este presente año de 1778.

\author{
[Al margen] \\ Testam $^{\text {to }}$. \\ Sacóse el día de su otorga \\ miento, en el papel del se \\ llo segdo., de q $\mathrm{q}^{\mathrm{e}}$. \\ doy fe.
}

En el Nombre de Dios todo Poderoso, y de su bendita Madre, la siempre Virgen María concebida en gracia y gloria desde el primer instante de su purísimo ser Amén= Sepan cuantos esta carta de mi testamento, última y final disposición vieren, como Yo $\mathrm{D}^{\mathrm{n}}$. Eusebio José33 Sánchez Pareja del Consejo de S.M: Regente Presidente de la Real Audiencia, Gobernador, y Capitán General de este Reyno de la Nueva Galicia, estando como estoy sano, y en pie, de que doy a Dios Nuestro Señor infinitas gracias, y por su Santa Bon[f. 284v.] dad en mi entero juicio, memoria, y entendimiento natural, creyendo como firme, y verdaderamente creo y confieso en el

32 Son tres los testamentos hallados de Eusebio Sánchez Pareja que abarcan el periodo de 1769 a 1778, y coinciden con momentos cruciales en su trayectoria profesional. El primero se encuentra en el Archivo de la Real Audiencia de Guadalajara (ARAG) y los otros dos en el Archivo de Archivo de Instrumentos Públicos del Estado de Jalisco (AIPEJ). Véase ARAG, Documento sobre la testamentaria de Eusebio Sánchez Pareja, del Consejo de Su Majestady Oydor de la Real Audiencia del reino de la Nueva Galicia, Ramo Civil, caja 108, exp. 1, ańo 1769 y AIPEJ, Nicolás López Padilla (escribano), vol. 2, 1771-1778, 4 de octubre de 1773, fojas, 139 f-144 v. y 11 de marzo de 1778, fojas, $284 \mathrm{f}-291 \mathrm{f}$.

${ }^{33}$ Es en éste, su tercer testamento, que Sánchez Pareja hace mención de su segundo nombre, José, apareciendo sólo como Eusebio Sánchez Pareja en los anteriores. 
Altísimo Misterio de la Santísima Trinidad, Dios Padre, Dios Hijo y Dios Espíritu Santo, tres personas distintas, y una sola esencia Divina: En el de la Encarnación del Verbo Eterno, en las Purísimas entrañas de María Santísima Nuestra Señora, y en todos los demás Misterios, que tiene, cree, y confiesa Nuestra Santa Madre Yglesia Católica Apostólica Romana, bajo de cuya fe, y creencia he vivido, y protesto vivir, y morir, como Católico y fiel cristiano, invocando como invoco por mis Patronos, Intercesores, y Abogados, a la Soberana Emperatriz de Cielos, y Tierra María Santísima Nuestra Señora en su vocación de la Concepción, Guadalupe, Angustias y Atocha, ${ }^{34}$ a su Purísimo, y Castísimo Esposo el $S^{\text {or }} S^{\mathrm{n}}$. José, a los Santos Apóstoles San Pedro, y San Pablo, Santo Ángel de mi Guarda, y Santo de mi Nombre, a el Gloriosísimo Señor San Antonio Abad, y a el de Padua, Señor $S^{\mathrm{n}}$. Francisco de Asís, y de Sales, y demás de la Corte Celestial, a quienes humildemente suplico, se interpongan con la Majestad Suprema, haya misericordia de mi Alma, cuando transite de esta vida temporal a la Eterna: $Y$ temiéndome de la muerte, que es cosa natural a [f. 285] toda criatura viviente, su término dudoso, la hora, y el cuándo incierto; deseoso de disponer en tiempo, y forma las cosas tocantes a el descargo de mi conciencia, para que mi Alma se salve, como lo espero de la infinita piedad de mi Creador,

\footnotetext{
${ }^{34}$ Siguiendo los formularios notariales, lo primero que se debía hacer por el testamento era invocar el nombre de Dios y confesar la santa fe católica, con todo lo que tiene y cree la Santa Iglesia Romana. Cfr. Martínez López-Cano, La política de escrituras, 170-184; sin embargo, más allá de la estructura común reproducida por el testamento de acuerdo a un formulario, la encomienda del alma a un conjunto más o menos amplio de intercesores o abogados celestiales, permite adentrarnos en escenarios más íntimos como las devociones o práctica de la piedad relacionados con una trayectoria vital; en este caso, las advocaciones marianas de Sánchez Pareja remiten, en primer lugar, a la asunción del ideario franciscano por la advocación de la Inmaculada Concepción, Patrona y Reina de esta orden religiosa; la alusión de la Virgen de Guadalupe remite a un culto cimentado a la par de su cursus honorum en la Nueva España donde hizo carrera burocrática, además cabe recordar que este culto fue en aumento a lo largo del siglo XvirI y en especial después de 1756 con la concesión papal del patronato e incremento de representaciones; igualmente, la mención a la Virgen de las Angustias nos remite a sus años de juventud y formación universitaria en Granada, ciudad de donde es patrona esta virgen; finalmente está la advocación a la Virgen de Atocha, patona de Madrid, advocación que además fue considerada desde el siglo xviı y xviı protectora de los reyes de España y patrona de la monarquía, lo cual hace patente el compromiso regalista de Sánchez Pareja.
} 
hago, y ordeno mi Testamento, última, y final disposición en la forma, $\mathrm{y}$ manera siguiente.

$1^{a}\left\{\right.$ Primeramente ${ }^{35}$ encomiendo mi Alma a Dios que la creó de la nada, y el Cuerpo a la Tierra de que fue formado, y quiero, y es mi voluntad que sea vestido, luego que muera, con el Hábito, o Sayal de mi Padre San Francisco, ${ }^{36}$ y que el Ataúd en que se deposite, se forre en el mismo Sayal, y que sobre él se ponga mi Beca Azul de Colegial, que soy del Real Colegio de Santa Catarina [sic] Mártir ${ }^{37}$ de la Universidad de Granada, ${ }^{38}$ la que traigo conmigo para este efecto, en honor, y reverencia de mi Santa Patrona, trasladándose dicho Ataúd, y mi Cuerpo en él depositado, a la Sacristía de esta Santa Iglesia Catedral, si muriere aquí, a las cuatro horas de haber fallecido, y desde donde quiero que se me haga el Entierro, y se me dé sepultura conforme se ha acostumbrado con los Señores Presidentes de esta Real Audiencia, ${ }^{39}$ mis Predecesores, diciéndoseme Misa de Cuerpo presente con su vigilia, siendo la hora proporciona-

${ }^{35}$ Se trata ésta de una cláusula decisoria sobre el momento final que muestra la mentalidad y prácticas de la época en relación con el enterramiento y servicios religiosos. Así, después de encomendar el alma a Dios, se dispone que el cuerpo vuelva a la tierra en remembranza del acto de creación divina, y se añade la elección de mortaja y sepultura. Cfr. Martínez López-Cano, La politica de escrituras, LxxI.

${ }^{36}$ La preocupación por conseguir indulgencias que restaran el tiempo de estancia en el purgatorio movía a los testadores a inclinarse por un hábito religioso a la hora de elegir mortaja, siendo el de San Francisco el más recurrente respecto a los demás.

${ }^{37}$ Véase Miguel A. López Rodríguez, "El Colegio de Santa Catalina Mártir (Granada, 1537-1802)", Archivo Teológico Granadino (54) (1991): 91-228; y María del Carmen Calero Palacios y J. A. Sánchez Marín, El Colegio de Santa Catalina Mártir: estudio de sus constituciones. Texto latino y traducción (Granada: Universidad de Granada, 1997).

${ }^{38}$ La universidad de Granada fue creada por Real Cédula de 7 de diciembre de 1526 dirigida al arzobispo Pedro Ramiro de Alba, por lo que tuvo una doble fundación: imperial y pontificia; contó las mismas prerrogativas y privilegios que las universidades de Bolonia, París, Salamanca y Alcalá de Henares y su creación estuvieron presentes los estudios jurídicos, coincidiendo en proyección con el resto de las universidades del reino, que estuvieron orientadas a las formación de cuadros para las administración civil y eclesiástica del Antiguo Régimen, Cfr. Inmaculada Arias de Saavedra, "Granada, una Universidad del Antiguo Régimen. La población universitaria durante el siglo XvIII", en Las universidades hispánicas: de la Monarquía de los Austrias al centralismo liberal, vol. II, Siglos XVIII y XIX, ed. Luis E. Rodríguez-San Pedro Bezares, 25-58 (Salamanca: Universidad de Salamanca, Junta de Castilla y León-Consejería de Educación y Cultura, 2000).

${ }^{39} \mathrm{El}$ primero de los testamentos redactados por Sánchez Pareja fechado el 9 de febre- 
da para ello, sin otra solemnidad, que aquella [f. 285 v.] que sea precisa, sobre que hago especial encargo a mis Albaceas: $Y$ en el caso de que mi fallecimiento se verifique en otra parte como Cartagena, o donde haya Convento de mi Padre San Francisco, quiero que en él se deposite mi Cuerpo difunto, y si no le hubiere, en la Yglesia que haga Cabecera del Pueblo, dejando a elección de mis Albaceas, si estuvieren presentes, y si no a la del Justicia mayor del Paraje, la disposición de mi Entierro, con la moderación, que llevo encargada.

\section{Ytt. Dejo a las Mandas forzosas, ${ }^{40}$ dos pesos, con que las separo, y aparto de mis bienes.}

3. Ytt. Mando que se me digan cien Misas con la Limosna acostumbrada, sin que por esto sea mi ánimo coactar a mis Albaceas, o Herederos, a que hayan de mandar decir las que puedan en sufragio de mi Alma, sacándoseme en el mismo día de mi fallecimiento, la Bula

ro de 1769, en esta parte del documento presenta al margen el siguiente inciso: "Ojo no correr esta cláusula” y este párrafo tachado:

"Yen euanto a la asistencia a mi entierro del Venerable Đeán y Cabilto, si siquiera eoneurrir gratis, en honor de la toga, y por ta buena correspondencia que tuve consu señoría venerable, to pueda ejecutar, y no de otro modo, esperando el premio de el todo Poderoso, en euio caso darán mis Albaceas a los señores todos, y a mi nombre las gracias te vida a esta última honra que me hagan, y de euyos costos no me permite gravar ta justicia de tos interesactos a mis bienes".

Sin lugar a dudas, la razón de esta rectificación de la última voluntad de Sánchez Pareja, tenía como base el enfrentamiento desatado en 1769 entre el Obispo de Guadalajara, Diego Rodríguez de Rivas y Velasco (1763-1770), con Sánchez Pareja y el fiscal de la Audiencia Domingo Arangoiti quienes habían acusado al prelado de incumplimiento de sus funciones y atropello a la jurisdicción real. El caso fue bastante grave y llegó a oídos del rey, quien obligó a los magistrados a retractarse en sus acusaciones. Cfr. ARAG, Cédula que envió el Rey de España para que se castigara al fiscal Don Domingo de Arangoiti y a Don Eusebio Sánchez Pareja Oidor, por las ofensas contra el obispo Don Diego Rodríguez de Rivas. Ramo Civil, caja 77, exp. 1, año 1769 y Don Francisco Galindo y Quiñones, en nombre de Don Eusebio Sánchez Pareja y Don Domingo Arangoiti, fiscal de la Rl. A. presentó disculpas al obispo de México por el supuesto agravio y ofensa. Ramo civil, caja 339, exp. 9, 1769.

${ }^{40}$ Era costumbre señalar que se apartaban de bienes para hacerlas cumplir. Eran mandas forzosas Guadalupe, S. Lázaro, S. Antón, Cruzada y Redención de cautivos. A estas mandas se les llamaba pías y también a todo aquello que se manda a las iglesias y cofradías, hospitales y monasterios y a pobres para redimir cautivos y para casar huérfanas; cfr. Martínez López-Cano, La politica de escrituras, LXII y 172. 
de Difuntos, ${ }^{41}$ y que a los tres días de hecho mi Entierro, se me hagan las honras, y exequias, reducidas a una Misa cantada, con su vigilia rezada, y asistencia de las Personas Religiosas, que convidasen mis Albaceas, y consideraciones que puedan asistir útilmente, pidiendo a Dios por la Salvación de mi Alma, huyendo siempre de ostentación, y pompa.

\section{Ytt. Declaro que soy natural de la Villa de Baena [f. 286] Reyno} de Córdoba, Provincia de Andalucía, en los Reynos de España, Familiar del Santo Oficio de la Inquisición de aquella Ciudad, y del número de dicha villa, hijo legítimo de $\mathrm{D}^{\mathrm{n}}$. José Sánchez, Administrador, que fue de la Real Renta de Salinas ${ }^{42}$ de ella, y de $\mathrm{D}^{\mathrm{a}}$. Rosa Francisca de Pareja, y Torre; Diputado que fui de Corte de Madrid, de dicho Real Colegio de Santa Catarina [sic] Mártir, ${ }^{43}$ de cuyas resultas, me confirió Su Majestad la Auditoria de la Gente de Guerra, y Tenencia de Gobierno, de la Ciudad, y Provincia de Cartagena de estas Yndias, con honores de Oydor de la Real Audiencia de Santo Domingo, ${ }^{44}$ a donde pasé el año de cuarenta,

${ }^{41}$ Eran aquellas que, a cambio de una aportación económica, concedían indulgencias, por las faltas y pecados; cfr. María del Pilar Martínez López-Cano, "El costo de una pronta salvación en Nueva España, siglos XVI-XvII", Revista de Historia y Ciencias Sociales Palimpsesto 1(2) (2004): s/p.

${ }^{42}$ De las muchas reformas introducidas por Ensenada, nombrado en 1743 responsable de la Hacienda real, está la decisión de asumir la administración directa de las llamadas rentas generales, entre las que se encontraba la de la sal, que dio comienzo en 1750. En el partido de Córdoba se encontraban, entre otras administraciones, las salinas de Baena, activas hasta el día de hoy. $C f$ r. Concepción Camarero Bullón, "Geografía de la sal a mediados del siglo XviII", Boletín de la Real Sociedad Geográfica (137-138) (2001-2002): 129-160.

${ }^{43}$ Entre las mandas declaradas por Eusebio Sánchez Pareja en su primer testamento de 9 de febrero de 1769, y ya no mencionadas en los siguientes, está la constitución de un censo de doscientos pesos para remitir al "rector y colegiales de dicho Real Colegio de Santa Catarina [sic] Mártir de la ciudad de Granada, en retribución de los beneficios, y auxilios, que recibí de su Señoría, así en el recibimiento de mi persona, por uno de sus colegiales, como en la Diputación a Corte, que confío a mi conducta" cuyo beneficio por réditos vencidos, se aplicarían a "beneficio del colegial que estuviere en turno en oposición a Prebendas Eclesiásticas"; cfr. ARAG, Documento sobre la testamentaria..., Ramo Civil, caja 108, exp. 1, ańo 1769.

${ }^{44}$ El título de Teniente de Gobernador y Auditor de Gente de Guerra de la Audiencia y Provincia de Cartagena con honores de oidor de la Audiencia de Santo Domingo, fue otorgado a Sánchez Pareja en 30 de julio de 1748 por Fernando VI, dado en el Buen 
y nueve ${ }^{45}$ habiendo casado allí, con la $S^{\text {ra }}$. Da . María Luisa Narváez, ${ }^{46}$ hija legítima de los Señores $\mathrm{D}^{\mathrm{n}}$. Juan Salvador de Narváez ${ }^{47}$ ya difunto, ${ }^{48}$ y de $\mathrm{D}^{\mathrm{a}}$. Catarina Antonia de la Torre, ${ }^{49}$ Condes de Santa Cruz de la Torre, y vecinos de dicha Ciudad, de cuyo Matrimonio, hemos tenido tres hijos, ${ }^{50}$ el primero de ellos varón,

Retiro. Era para suceder a Dn. Miguel de Torrecilla y Gamino, y contaba con un salario de 500 ducados anuales. AGI, Contratación 5490, N. 1, R. 36.1749

${ }^{45}$ Sánchez Pareja recibió licencia para pasar a Indias el 10 de septiembre de 1748 llevando consigo dos baúles con ropa y libros, iba acompañado de dos criados llamados Salvador García de 19 años de edad, originario de la ciudad de Cádiz, y Domingo Ignacio Marbrella de 23 años, natural de la villa de Baena. Al momento de embarcar, Sánchez Pareja contaba 33 ańos y estaba soltero, AGI, Contratación 5490, N.1, R. 36. 1749.

${ }^{46}$ Tanto por línea paterna como materna, pertenecía a una de las principales familias criollas de la ciudad de Cartagena de Indias, con destacados miembros al servicio de la Corona y vinculados al cabildo secular, véase: Ma. del Carmen Borrego Pla: "Tiempos nuevos, reformismos y viejas resistencias", en Cartagena de Indias: la andadura de una vida bajo la colonia (Bogotá: El Áncora, 2010), 455.

${ }^{47}$ Juan Salvador Narváez y Berrio, conde de Santa Cruz de la Torre era al igual que Sánchez Pareja, de origen peninsular e hizo carrera en América, llegando a ser gobernador de Girón, cerca de Tunja. Inició su trayectoria al servicio de la Corona en 1721 como cadete en el batallón fijo de Cartagena de Indias hasta 1726 año que por un corto periodo de tiempo vuelve a la península. A su regreso, sus intereses se dirigieron a la administración local; primero, como alcalde ordinario de la ciudad y luego como alférez real. Sus nexos en Cartagena de Indias se fortalecieron al contraer matrimonio con la Condesa de Santa Cruz de la Torre, Catalina Antonia de la Torre, criolla nacida a comienzos del siglo XVIII en esta misma ciudad. En 1739 fue trasladado a Portobelo, donde luchó a las órdenes del gobernador contra las fuerzas inglesas comandadas por el almirante Vernon y, tras su destrucción, aportó recursos propios para costear las urgentes necesidades de la plaza; por todos estos méritos sería nombrado alférez mayor por del virrey Eslava (1740-1749) para administrar el avituallamiento de esta ciudad y uno de los más importantes puertos de exportación de la plata de Nueva Granada y salida de la Flota de Indias. A todos estos méritos se sumaba la relación familiar establecida con Eusebio Sánchez Pareja por ser segundo asesor del virrey Solís (1753-1761) y haber contraído nupcias con su hija María Luisa. Cfr. Margarita Restrepo Olano, Nueva Granada, 189-190.

${ }^{48}$ En este testamento, es el único en el que se omite el segundo apellido del suegro (Berrio), posiblemente, por haber fallecido para entonces.

${ }^{49}$ Era nieta de Toribio de la Torre y López, un español avecindado en la ciudad de Santa Marta, a donde llegó a fines del siglo XviI y fundó la hacienda de trapiche Santa Cruz de Papare, que más tarde abandonó ante los ataques de los piratas para trasladarse a la ciudad de Mompox, desde donde ejercería su administración, Cfr. Hugues Sánchez Mejía, "Haciendas de trapiche, hatos, hatillos y 'rozas', el mundo rural en la Gobernación de Santa Marta (1700-1810)", Historia del Caribe XI(28) (enero-junio 2016): 241-274.

${ }^{50}$ En 1769, al redactar su primer testamento, Sánchez Pareja sólo contaba con dos de sus tres hijos y así lo plasma en el documento. 
nombrado Joaquín María, ${ }^{51}$ de edad hoy de nueve años, y Cadete de Reales Guardias Españolas, con Real Dispensa de [f. 286 v.] su memoria, y las dos hembras, ${ }^{52}$ nombrada la mayor María Manuela, ${ }^{53}$ y la menor María Josefa,,${ }^{54}$ nacidos todos en esta Ciudad, a donde vine promovido de Oydor de esta Real Audiencia, el año de sesenta, y cuatro, pasando después a la de México, de Alcalde del Crimen, de que fui ascendido a Oydor, y últimamente a la Plaza de Regente de esta Real Audiencia, con las facultades, y prerrogativas de la Presidencia, de que tomé posesión el veinte, y uno de Abril del año próximo pasado de mil setecientos setenta, y siete.

5. Ytt. Declaro, que dicho mi hijo Joaquín María, es sucesor a el título de Castilla, de que hoy usan sus Abuelos maternos, y derechos de su Casa, faltando sus tíos el Teniente Coronel $\mathrm{D}^{\mathrm{n}}$. Antonio Narváez,

${ }^{51}$ Joaquín María, José, Juan, Salvador, Antonio, nació en la ciudad de Guadalajara en 21 de agosto de 1768, y no en 1758 como se registra en el primer testamento; fue bautizado el 29 de dicho mes en el sagrario de la catedral. Lo bautizó el obispo de Guadalajara, Dr. Don Diego Rodríguez de Rivas y su padrino de brazos fue el presidente de la Audiencia D. Francisco de Ayza, Marqués de Ayza. Family Search: Ciudad de Guadalajara, Parroquia: Sagrario Metropolitano, Bautizos: 1765-1771, Imagen: 345 de 631.

${ }^{52}$ Las dos hijas de Sánchez Pareja casaron en la ciudad de México el 14 de septiembre de 1788 en la Parroquia de la Asunción del Sagrario Metropolitano con los hijos del matrimonio habido entre Don Juan Manuel Fernández de Azipreste y doña Francisca Paula de Ugarte, difunta al momento del enlace. Éstos eran Manuel Fernández de Azipreste Ugarte que casó con María Manuela, y Francisco Fernández de Azipreste que casó con María Josefa y en 1797 tuvieron a José María de la Merced. Family Search: Ciudad de México, Parroquia: Asunción Sagrario Metropolitano (centro), Matrimonios Españoles: 1769-1779, 1780-1781, 1785-1791, Imagen: 741 de 791, Acta de Matrimonio de Manuel Fernández de Azipreste y María Manuela, hija legítima de Eusebio Sánchez Pareja y María Luisa Narváez y la Torre, 14 de septiembre de 1788.

${ }^{53}$ María Manuela, Josefa de la Ascensión, Catalina, Antonia nació en Guadalajara el 24 de mayo de 1770 . Fue bautizada el $1^{\circ}$ de junio de ese mismo año, por el Bachiller Don Antonio José Lozano y fue su padrino de brazos el obispo Dr. Don Diego Gómez de Parada. El ceremonial contó con los miembros del cabildo catedralicio. Family Search: Ciudad de Guadalajara, Parroquia: Sagrario Metropolitano, Bautizos: 1765-1771, Imagen: 536 de 631.

${ }^{54}$ María, Josefa, Luisa, Andrea, nació el 10 de noviembre de 1771 en Guadalajara. Fue bautizada, como sus hermanos, en el Sagrario de la Iglesia Catedral por Br. Don Manuel Caballero Sánchez Samaniego Presbítero secretario de Cabildo y fue su Padrino el Sr. Dr. Dn. Juan Baptista Arias Canónigo de esta Sta Yglesia Catedral y Comisario del Sto. Oficio Family Search: Ciudad de Guadalajara, Parroquia: Sagrario Metropolitano, Bautizos: 1771-1775, Imagen: 79 de 608, Acta de Bautizo de María Josefa Luisa Andrea, hija legítima de Eusebio Sánchez Pareja y María Luiza Narváez y la Torre, 18 de noviembre de 1771. 
Gobernador, y Comandante de la Ciudad, y Provincia de Santa Martha ${ }^{55}$ y $\mathrm{D}^{\mathrm{n}}$. Ignacio de Narváez, ${ }^{56}$ hermanos mayores de la expresada $S^{\text {ra }}$. su Madre, ambos solteros, y sin inclinación a el estado de Matrimonio, según me han significado; pues aunque tiene otras hermanas, una de ellas viuda, y con una hijita, y la otra recién casada, todas son menores respecto de mi mujer, pudiendo solo entrar a la opción de este título, y demás acciones, por defecto de esta línea; teniendo también derecho a el título de Castilla, de Marqués del Moral, que hoy posee su tío $\mathrm{D}^{\mathrm{n}}$. Bernardo de Bertodaño, y Narváez, Caballero del [f. 287] Orden de Santiago, ${ }^{57}$ Teniente Coronel de los

${ }^{55}$ El mariscal de campo de los Reales Ejércitos don Antonio de Narváez y La Torre, cuñado de Sánchez Pareja fue un ilustre militar e ingeniero destacándose como discípulo del ingeniero militar Don Antonio de Arévalo y distinguiéndose posteriormente como uno de los más brillantes constructores de fortificaciones. Fue asesor de Cartagena de Indias y gobernador de Santa Marta y Riohacha (1777-1778), así como de Panamá (1781). Se casó en Santa Marta, en 1786, con María Isidora Fernández de Castro. Cfr. Armando Martínez Garnica y Daniel Gutiérrez Ardilla, editores académicos, Quién es quién en 1810. Guia de forasteros del Virreinato de Santa Fe, Colección Memoria Viva del Bicentenario (Bogotá: Editorial Universidad del Rosario, 2010), 23; y Sergio Elías Ortiz, comp., Escritos económicos. Antonio de Narváez, Ignacio Pombo (Bogotá: Archivo de la Economía Nacional, Colección Bicentenario, Banco de la República, 2010), 13.

${ }^{56}$ Miembro del consulado de Comercio, participó en el comercio de exportación de aguardientes a los catalanes, manifestando que como importadores su éxito se debía a no tener inconveniente en venderlo en puestos o tiendas pequeñas AGI, Santa Fe, 957, Ignacio Narváez y la Torre, Cartagena, 10 de Julio de 1791, citado en Antony Mc Farlane, "Comerciantes y monopolio en la Nueva Granada. El Consulado de Cartagena de Indias", Anuario Colombino de Historia Social y Cultural (11) (1983): 43-69

${ }^{57}$ Bernardo Bertodano y Narváez, era teniente de fragata de la Real Armada y ayudante mayor general del Departamento de Marina de Cartagena de Indias. Era también caballero de la orden de Santiago y capitán agregado del Regimiento de Dragones de Lusitania. Casó en Valencia con la viuda de Vicente Pueyo y Neyró. De Vicente Pueyo y Neyró se tienen los siguientes datos: fue capitán de dragones retirado y procedía de una familia de tradición comercial y aspiraciones a participar en la política local lo cual se concreta con la compra de una regiduría; casó con Leonor del Moral y Bertolano, quien pasaría a ser más tarde marquesa del Moral, murió sin herederos en 1672. Su viuda, como única sucesora, solicitó el título de regidor por juro de heredad que había sido propiedad su marido, y se le concedió en 1762. La viuda de Pueyo contrajo nuevas nupcias con un pariente suyo: Bernardo Bertolano y Narváez, ambos procedían de las Indias. Leonor del Moral de Santiago de León, de Caracas, y su esposo de Cartagena de Indias. La primera vez que la documentación los registra como marqueses del Moral es en 1772, no pudiendo precisar la fecha exacta en que se adquirió el título. Desde la muerte del teniente de Regidor, hasta mayo de 1783, sería Bernardo Bertodano el que desempeñaría el oficio del que era propietaria su esposa, no sin ciertas dificultades. A raíz de su ausencia 
Reales Ejércitos, y Comandante del Regimiento de Dragones de Lusitana, y residente hoy en Valencia, primo hermano de la referida su Madre, por hijo legítimo de $\mathrm{D}^{\mathrm{a}}$. María Magdalena Narváez, ${ }^{58}$ hermana entera de mi Señor el Conde de Santa Cruz, y del Teniente de Coronel $\mathrm{D}^{\mathrm{n}}$. Carlos de Bertodano, ya difunto, no teniendo sucesión.

6. Ytt. Declaro, que dicha $S^{\text {ra }}$. Da . María Luisa de Narváez, mi mujer, y yo hemos criado un Nińo, que nos expusieron en Cartagena, el día veinte, y ocho de Junio, víspera de Sn. Pedro el año de sesenta, y cuatro, nombrado Pedro José, a quien hemos traído en nuestra compañía, y hoy se halla de Colegial en el Seminario del $S^{r}$. $S^{n}$. José de esta Ciudad, conocido por $\mathrm{D}^{\mathrm{n}}$. Pedro José Sánchez Pareja, no es mi hijo, ni sabemos quiénes fueron sus Padres, y solo tuvimos indicios de que lo fueron personas de distinción, y de calidad de Cartagena, pero quiero, y encargo a mi Mujer, e hijos, que lo traten como si lo fuera, y con el mismo amor que hasta aquí se han manejado, usando con él de toda humanidad y auxiliándole en su carrera de Estudios, para que logre su aprovechamiento en lo espiritual, y temporal, sirviendo a Dios, y cooperando a el único necesario de la salvación de su Alma, a que puede contribuir el que se ordene, mediante la Capellanía de ocho mil pesos de principal, que dejó dispuesta $\mathrm{D}^{\mathrm{n}}$. Pedro Caballe[f. 287 v.] ro Galán, que Dios haya, en su Memoria Testamentaria, llamándole en primer lugar a su sucesión, y por su falta a mis hijos, cuyos autos corren en Provincia.

forzosa de Valencia por sus obligaciones como comandante de escuadra del Regimiento de Dragones de Lusitania, Bernardo Bertodano solicitó de la Cámara la concesión de una Cédula de preeminencia, ya que el Ayuntamiento le había denegado el sueldo y demás emolumentos correspondientes al oficio de regidor. La muerte de Leonor del Moral, en 1783, convertiría a su segundo esposo en el nuevo propietario de la regiduría de la clase de nobles. Bernardo Bertodano formalizó su testamento en 1784 dejando como heredero a un primo hermano: José Zenón de Bertodano y Lautier. En dicho testamento fundaba, a su vez un mayorazgo con todos sus bienes. El primer Marqués del Moral falleció en Valencia el 14 de febrero de 1784. Cfr. Encarnación García Monerris, La monarquía absoluta y el municipio borbónico: la reorganización de la oligarquía urbana en el ayuntamiento de Valencia (1707-1800) (Madrid: Consejo de Investigaciones Científicas, 1991), 174-176.

${ }^{58}$ María Magdalena de Ventaja Narváez y Berrio, fue bautizada en Cartagena de Indias el 22 de agosto de 1699, donde casó el 25 de marzo de 1727 con Carlos Bertodano, bautizado en Sevilla el 23 de enero de 1705. 
7. Ytt. Declaro, que $\mathrm{D}^{\mathrm{n}}$. José Miranda, mi apoderado en Madrid, corre actualmente con varios encargos míos, y para sus costos le he enviado algunos pesos, y últimamente, cuatrocientos pesos por la vía de $\mathrm{D}^{\mathrm{n}}$. Miguel Lazo, mi correspondiente en Vera Cruz, en esta Flota, con que puede quedar pagado de lo que haya suplido en la saca de los Títulos de Regente de esta Real Audiencia, que corrió por su mano, y en la compra de unos Libros, Relación de mis méritos, y alguna otra cosa ligera, y satisfecho un pico que quedé restando a su Antecesor $\mathrm{D}^{\mathrm{n}}$. Andrés Maján y Moreno.

8. Ytt. Declaro que dicha ${ }^{\text {ra }}$. D ${ }^{\text {a }}$. María Luisa de Narváez, mi Mujer, trajo a el Matrimonio dos Esclavas nombrada la una María Melchora, y la otra María Hilaria, ambas mulatas, correspondiéndole también el Negrito cocinero, nombrado José María, y que también trajo sus aderezos de Diamantes, y esmeraldas, Alhajas de oro, Anillos, y varios vestidos [f. 288] de su uso, que recibí sin avalúo, y quinientos pesos de la dote de una Obra pía, en que la anotó el Ilmo. $S^{r}$. $D^{r}$. $D^{\mathrm{n}}$. Bartolomé Narváez obispo de Cartagena ${ }^{59}$ su Tío, y hermano entero de mi Señor el Conde de Santa Cruz, que todo pudo componer la cantidad de dos mil, y quinientos pesos, y deberá percibir a su tiempo, con los gananciales que le corresponden.

9. Ytt. Declaro, que tuve cuentas con $\mathrm{D}^{\mathrm{n}}$. Francisco Álvarez de Castro, Marqués de Bellestar ${ }^{60}$, ya difunto, vecino que fue de Cartage-

${ }^{59}$ El Dr. Don Bartolomé de Narváez y Berrio fue obispo de Cartagena entre 1751 y 1754, engrosó el escaso número de criollos que alcanzó esta distinción. Hijo de Bartolomé de Narváez y Juana Francisca Berrio nació en Cartagena de Indias; en 1713 entró a estudiar en el colegio de San Bartolomé. Fue canónigo de la iglesia de Cartagena y presentado para la diócesis en 1752 gobernándola hasta su muerte acaecida en Santa Cruz de Lorica mientras realizaba una visita pastoral; sus restos fueron enterrados en la ermita de paja de esa ciudad. Cfr. Manuel Serrano García, "El obispado de Cartagena de Indias en el sigo XviII (Iglesia y poder en la Cartagena colonial)” (Tesis de doctorado, Universidad de Sevilla, 2015), 111.

${ }^{60}$ Bellestar, Marqués, título de Aragón concedido en 20 de noviembre de 1690 a don Feliz Costa y Garcés, Caballero de Santiago. El 30 de enero de 1758 se obtuvo real permiso para enajenar el Título, recibiéndolo don Francisco Álvarez de Castro, vecino de Cartagena de Indias (Perú), sus hijos, herederos y sucesores, perpetuamente por Real Despacho en 13 de mayo de 1766. Cfr. Ampelio Alonso de Cadenas y López, Títulos 
na, las cuales nunca se concluyeron, ni ajustamos, y por muerte del susodicho, se transfirió con su Albacea, Tutor, y Curador de los menores que dejó mi Apoderado General, que lo fue en aquella Ciudad, mi suegro el Sor. Conde de Santa Cruz, que Dios haya, dándonos por satisfechos mutuamente, y finiquitados, como constará del documento de transacción, que se quedó allí, y no me remitió mi Señor; siendo no obstante mi voluntad, que si en algún tiempo se aclarase contra mi algún descubierto, a beneficio de los herederos del Marqués, se les satisfaga por mis Albaceas, encargándoles, y a mis hijos, que aún sin esta circunstancia, atiendan siempre a los susodichos [f. 288 v.] menores, auxiliándolos con los Reales, que puedan habida consideración a la buena armonía, y amistad que llevamos el Marqués, y Yo; y a la duda en que estuve siempre de quien a quien se alcanzaba, porque en los encargos míos, que manejó, estuvimos a la confianza, y no se llevó la formalidad que correspondía, y sí sólo de algunos apuntes, de los cuales se encontrarán varios entre mis papeles, con uno de resguardo de su puño, y letra que me hizo de cantidad de ocho mil, y más pesos en el viaje que hice a España, el año de cincuenta, y tres a cincuenta, y cinco.

10. Ytt. Declaro, que $D^{n}$. Manuel Sánchez Pareja ${ }^{61}$ mi hermano, Capitán de Granaderos, que fue del Regimiento de Lisboa, y Corre-

vacantes y titulos extranjeros cuyo uso fue autorizado en España, recopilado y redactado por ediciones de la revista Hidalguí, Apéndice II (Madrid: Gráficas Arias Montano, S.A. Móstoles, 1991), 17.

${ }^{61}$ La noticias que tenemos es que, al igual que Eusebio, nació en Baena, provincia de Córdoba, España, en torno a 1712. El 6 de noviembre de 1742 el rey le encargó la compañía de Granaderos del tercer batallón del regimiento de infantería de Lisboa con el grado de capitán. En 1745 le nombró corregidor de la ciudad y provincia de Tocayma y Mariquita por un periodo de cinco años. En el nombramiento se indicaba que en caso de no poder servirlo lo hicieran en su lugar Gregorio Sánchez Pareja o Fernando [Vicente] Sánchez Pareja con la aprobación el virrey de Santa Fe. Posteriormente fue nombrado por el virrey Solís corregidor y justicia mayor de Quito en 1754 . Tuvo otras encomiendas de parte del virrey Solís como el cobro de deudas pendientes. En 1763 solicitó el corregimiento de México con el grado de coronel, avalado por sus méritos y los de sus familiares, Cfr. Montserrat Domínguez, "El corregidor Manuel Sánchez Osorio y Pareja en la Real Audiencia de Quito", en América, poder conflicto y política, coord. Gabriela DallaCorte Caballero, Ricardo Piqueras Céspedes, Meritxell Tous Mata (Murcia: Asociación Española de Americanistas, Universidad de Murcia, 2013). 
gidor de la ciudad de San Francisco de Quito, por Su Majestad, murió allí, ejerciendo este empleo, en primero de diciembre de mil setecientos sesenta, y seis, bajo de disposición testamentaria, en que me instituyó por heredero, y al difunto mi hermano $\mathrm{D}^{\mathrm{n}}$. Fernando Sánchez, ${ }^{62}$ teniente de Infantería, y Ayudante mayor, que fue del Regimiento de la Corona, que falleció de Corregidor de la ciudad de Zacatecas, en este Reyno, por Marzo del año pasado de setecientos sesenta, y siete, con otros herederos, que nombró sus sobrinos, $\mathrm{y}$ míos, hijos de hermanos difuntos, y entre ellos a $\mathrm{D}^{\mathrm{n}}$. Salvador Sánchez [f. 289] Pareja, Tesorero Oficial Real de la ciudad de Quito, a quien también dejó de Albacea, en compañía de su yerno $\mathrm{D}^{\mathrm{n}}$. Manuel de la Guardia, oficial Real de la Villa de Cuenca, correspondiente al distrito de aquella Real Audiencia, habiéndome prelegado [sic], o hecho la manda particular, del Espadín, Caxeta, y juego de hebillas de oro, de su uso; sobre cuya recaudación di Poder a dicho mi Señor el Conde de Santa Cruz, y a mis hermanos $\mathrm{D}^{\mathrm{n}}$. Antonio y $\mathrm{D}^{\mathrm{n}}$. Ignacio Narváez; sin que hasta ahora se haya verificado en el todo, o en parte: en consecuencia de lo cual encargo a mis Albaceas, que hagan las diligencias, que convengan, a fin de este cobro; encargándoles, y a mi hijo Joaquín María, que no enajenen las referidas Alhajas, en tiempo alguno, conservándolas dicho mi hijo, por memoria de su tío, y usando solo de ellas, a excepción del caso de necesidad.

11. Ytt. Declaro, que el citado $\mathrm{D}^{\mathrm{n}}$. Fernando Sánchez, mi hermano, dejó por su fallecimiento, seis hijos, los cinco varones, y la una hembra, en su viuda, que hoy vive, natural de Veracruz, nombrada $D^{a}$. Josefa Xaviera Penagos, los cuales se llaman $\mathrm{D}^{\mathrm{n}}$. Fernando, Capitán a Guerra, y Alcalde mayor que fue de Autlán; $\mathrm{D}^{\mathrm{n}}$. Vicente, $\mathrm{D}^{\mathrm{n}}$. José, teniente de Milicias Españolas, $D^{\mathrm{n}}$. Nicolás, $\mathrm{D}^{\mathrm{n}}$. Eusebio, y $\mathrm{D}^{\mathrm{a}}$. María Josefa, casada en Oaxaca con $\mathrm{D}^{\mathrm{n}}$. Salvador Dolz, vecino allí arraigado, de distinción, los que han sucedido en el $\mathrm{D}^{\mathrm{ro}}$. de su Padre, en la parte [f. 289 v.] que le instituyó heredero, el referido su hermano,

${ }^{62}$ Vicente Fernando Sánchez Pareja, fue nombrado corregidor interino de la Provincia de Zacatecas, tomando posesión del cargo el día 5 de febrero de 1766; falleció a principios de mayo de 1767. 
y mío $\mathrm{D}^{\mathrm{n}}$. Manuel; encargo a mis albaceas, y particularmente a mis hijos Joaquín María, María Manuela, y María Josefa, que hayan, y tengan toda aquella buena correspondencia, que es debida, con dichos mis sobrinos, ayudándolos, y socorriéndolos en lo que hubiere lugar: Declarando que en esta Ciudad, se halla también con destino de fiel Administrador de Almacenes, en la Real Factoría de Tabacos, $\mathrm{D}^{\mathrm{n}}$. Andrés de Corpas, mi sobrino, por hijo de mi hermana, $\mathrm{D}^{\mathrm{a}}$. María Anna Sánchez, y de D ${ }^{\mathrm{n}}$. Bonoso Teodoro de Corpas, su marido, Juez Administrador General, que fue de la Renta Real de Salinas de la ciudad de Cádiz, ambos difuntos, a quien encargo igual buena armonía con sus Primos.

12. Ytt Declaro, que por línea Paterna, soy descendiente de la Ciudad de Murcia, por hijo de dicho $S^{\text {or }}$. mi padre $\mathrm{D}^{\mathrm{n}}$. José, natural que fue de ella, y nieto paterno de $\mathrm{D}^{\mathrm{n}}$. Jacinto Sánchez, y de $\mathrm{D}^{\mathrm{a}}$. María García Álvarez Osorio, proveniente de la Villa de Moratalla, en aquel Reyno, de cuya ascendencia, y de otros ul [f. 290] teriores progenitores, su limpieza de sangre, legitimidad, y nobleza, consta de varios Documentos, y Testimonios, que se hallarán entre mis Papeles, entre los cuales, están los goces, o recibimientos, a el estado de Nobles, de mi Padre $\mathrm{D}^{\mathrm{n}}$. José, de mi Abuelo Paterno $\mathrm{D}^{\mathrm{n}}$. Jacinto, el mío, y el de mis hijos, en el Cabildo de esta ciudad, e igualmente se hallan los respectivos, a mi línea materna.

13. Y para cumplir, y pagar este mí Testamento, y las mandas en él contenidas, nombro por mi Albacea testamentaria, Fidey-comisaria, y tenedora de bienes a la dicha $S^{r a}$. D ${ }^{a}$. María Luisa de Narváez, mi mujer, para que después de mi fallecimiento, entre, y se apodere en todos mi bienes, y los venda en Almoneda, o fuera de ella, como le pareciere, y por bien tuviere, y con su procedido, cumpla, y ejecute este mi testamento, para lo cual, a más del término, que el $\mathrm{D}^{\text {ro }}$. dispone, le prorrogo el que necesitare, y hubiere menester; declarando, como declaro por bienes míos, y de dicha señora, habidos constante Matrimonio, a excepción de los arriba expresados, la plata labrada, Coches, Mulas, y Muebles, que se hallan dentro de Casa, y los pesos que pueda haber existentes a el tiempo de mi fallecimien- 
to, y manifieste dicha [f. 290 v.] Señora por una descripción que haga del estado de dichos mis bienes, sin que se le pueda obligar a otra formalidad de Inventario, conforme a una Ley de Partida, y a la costumbre de esta Real Audiencia, y la de México, que relevan a los Padres, de estos Inventarios, sujetándolos solo a la descripción.

14. Y en el remanente que quedare de todos mis bienes, deudas, $\mathrm{D}^{\text {ros }}$, y acciones, que en cualquiera manera me toquen, $\mathrm{y}$ pertenezcan, puedan, y deban tocarme, y pertenecerme, instituyo, y nombro por mis únicos, y universales herederos, a los referidos mis hijos legítimos, y de dicha Señora $\mathrm{D}^{\mathrm{a}}$. María Luisa, $\mathrm{D}^{\mathrm{n}}$. Joaquín María, $\mathrm{D}^{\mathrm{a}}$. María Manuela, y $\mathrm{D}^{\mathrm{a}}$. María Josefa, para que lo que fuere lo hayan, hereden, y gocen con la bendición de Dios, y la mía; y a dicha Sra. Da. María Luisa, su Madre, por su Tutora, y Curadora, substituyéndola pupilarmente a dichos mis hijos si murieren intra pubertatem; y faltando mis hijos antes que Yo muera, instituyo, y nombro por mi única, y universal Heredera a dicha Seńora Da. María Luisa, atendiendo a el mucho amor que nos tenemos, y a su distinguida calidad, y circunstancias personales que le hacen acreedora a toda mi estimación y gratitud.

15. Y por el presente, revoco, anulo, doy por ningunos, de ningún valor ni efecto, otros cualesquiera Tes[f. 291] tamentos, Codicilos, ${ }^{63}$ Memorias, Poderes para testar, y otras últimas disposiciones, que antes de esta haya fecho, u otorgado, por escrito, de palabra, o en otra forma, para que no valgan, ni hagan fe en juicio, ni fuera de el, salvo el presente, que ahora otorgo, que quiero se guarde, cumpla, y ejecute por tal mi testamento, última y final disposición, o por aquel instrumento que mejor haya lugar en $\mathrm{D}^{\text {ro }}$. Y el S ${ }^{\text {or }}$. Otorgante, a quien Yo el Escribano de S. M. doy fe, que conozco, también la doy, de que a lo que notoriamente parece está en su entero juicio, memoria, y entendimiento natural, sano, y en pie, y así lo otorgó, y firmó

${ }^{63}$ En derecho romano, conjunto de disposiciones de última voluntad salvo la institución de heredero o la desheredación; no requiere las formalidades de un testamento y a menudo es una modificación del mismo. 
su Sria. en este registro, en la ciudad de Guadalajara a once de marzo de mil setecientos setenta, y ocho ańos; siendo testigos rogados, $\mathrm{y}$ llamados para este efecto $\mathrm{D}^{\mathrm{n}}$. José Celis, $\mathrm{D}^{\mathrm{n}}$. Juan José Villegas, $\mathrm{y}^{\mathrm{n}}$. Agustín del Castillo, presentes, $\mathrm{y}$ vecinos $=$ entre renglones $=\mathrm{de}=$ vale=

Don Eusebio Sánchez Pareja [firma]

Ante mí, Nicolás López Padilla, SS ${ }^{\text {no }}$. R'. [firma]

Gratis y así lo juro 